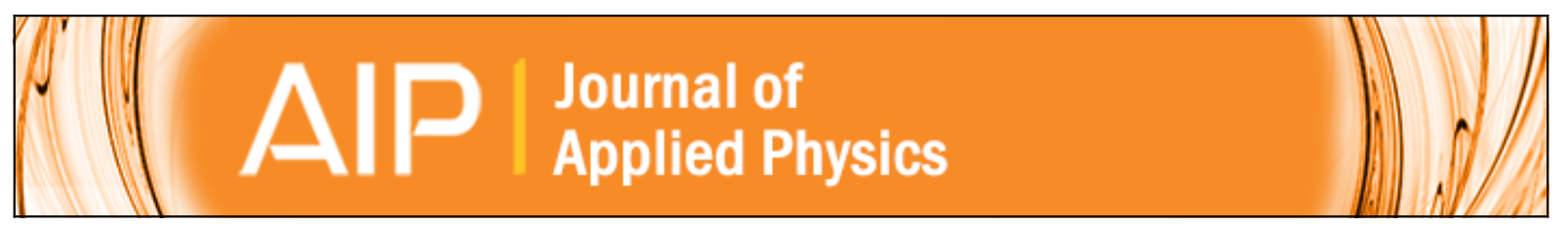

\title{
Bulk plasma fragmentation in a C4F8 inductively coupled plasma: A hybrid modeling study
}

Shu-Xia Zhao, Yu-Ru Zhang, Fei Gao, You-Nian Wang, and Annemie Bogaerts

Citation: Journal of Applied Physics 117, 243303 (2015); doi: 10.1063/1.4923230

View online: http://dx.doi.org/10.1063/1.4923230

View Table of Contents: http://scitation.aip.org/content/aip/journal/jap/117/24?ver=pdfcov

Published by the AIP Publishing

\section{Articles you may be interested in}

Test particle simulation of the role of ballistic electrons in hybrid dc/rf capacitively coupled C $\mathrm{F} 4$ plasmas

J. Vac. Sci. Technol. A 27, 287 (2009); 10.1116/1.3072922

Control of ion species in inductively coupled oxidation plasma by inert gas mixing

J. Appl. Phys. 100, 113303 (2006); 10.1063/1.2363255

Investigation and modeling of plasma-wall interactions in inductively coupled fluorocarbon plasmas

J. Vac. Sci. Technol. A 22, 689 (2004); 10.1116/1.1722614

C $4 \mathrm{~F} 8$ dissociation in an inductively coupled plasma

J. Vac. Sci. Technol. A 21, 1038 (2003); 10.1116/1.1582456

Global model and scaling laws for inductively coupled oxygen discharge plasmas

J. Appl. Phys. 86, 3536 (1999); 10.1063/1.371255

Frustrated by

old technology?

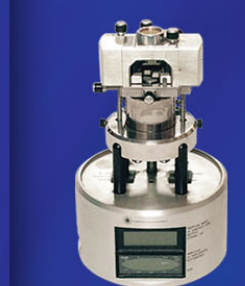

Is your AFM dead

and can't be repaired?

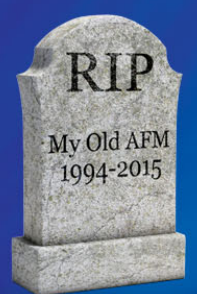

Sick of bad customer support?

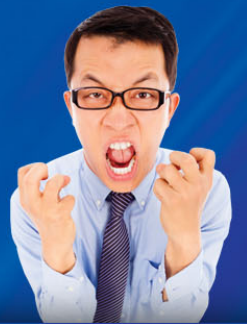

It is time to upgrade your AFM

Minimum $\$ 20,000$ trade-in discount for purchases before August 31st

Asylum Research is today's technology leader in AFM 


\title{
Bulk plasma fragmentation in a $\mathrm{C}_{4} \mathrm{~F}_{8}$ inductively coupled plasma: $\mathrm{A}$ hybrid modeling study
}

\author{
Shu-Xia Zhao, ${ }^{1,2}$ Yu-Ru Zhang, ${ }^{1,2}$ Fei Gao, ${ }^{1}$ You-Nian Wang, ${ }^{1}$ and Annemie Bogaerts ${ }^{2}$ \\ ${ }^{1}$ School of Physics and Optoelectronic Engineering, Dalian University of Technology, Dalian 116024 , \\ People's Republic of China \\ ${ }^{2}$ Research Group PLASMANT, Department of Chemistry, University of Antwerp, Universiteitsplein 1, B-2610 \\ Antwerp, Belgium
}

(Received 17 January 2015; accepted 12 June 2015; published online 30 June 2015)

\begin{abstract}
A hybrid model is used to investigate the fragmentation of $\mathrm{C}_{4} \mathrm{~F}_{8}$ inductive discharges. Indeed, the resulting reactive species are crucial for the optimization of the Si-based etching process, since they determine the mechanisms of fluorination, polymerization, and sputtering. In this paper, we present the dissociation degree, the density ratio of $\mathrm{F}$ vs. $\mathrm{C}_{\mathrm{x}} \mathrm{F}_{\mathrm{y}}$ (i.e., fluorocarbon (fc) neutrals), the neutral vs. positive ion density ratio, details on the neutral and ion components, and fractions of various fc neutrals (or ions) in the total fc neutral (or ion) density in a $\mathrm{C}_{4} \mathrm{~F}_{8}$ inductively coupled plasma source, as well as the effect of pressure and power on these results. To analyze the fragmentation behavior, the electron density and temperature and electron energy probability function (EEPF) are investigated. Moreover, the main electron-impact generation sources for all considered neutrals and ions are determined from the complicated $\mathrm{C}_{4} \mathrm{~F}_{8}$ reaction set used in the model. The $\mathrm{C}_{4} \mathrm{~F}_{8}$ plasma fragmentation is explained, taking into account many factors, such as the EEPF characteristics, the dominance of primary and secondary processes, and the thresholds of dissociation and ionization. The simulation results are compared with experiments from literature, and reasonable agreement is obtained. Some discrepancies are observed, which can probably be attributed to the simplified polymer surface kinetics assumed in the model. (c) 2015 AIP Publishing LLC. [http://dx.doi.org/10.1063/1.4923230]
\end{abstract}

\section{INTRODUCTION}

$\mathrm{C}_{4} \mathrm{~F}_{8}$ gas mixtures are widely used for the selective etching of $\mathrm{SiO}_{2}$ over $\mathrm{Si}$ because of their attractive chemistry properties. ${ }^{1,2}$ It is well known that $\mathrm{C}_{4} \mathrm{~F}_{8}$ plasmas contain many abundant fluorocarbon (fc) radicals for polymerization, ${ }^{3,4}$ such as light $\mathrm{CF}_{\mathrm{x}}$ radicals, but also heavy polymeric $\mathrm{C}_{\mathrm{x}} \mathrm{F}_{\mathrm{y}}(\mathrm{x} \geq 2)$ species. Therefore, the etch selectivity of $\mathrm{C}_{4} \mathrm{~F}_{8}$ plasma is normally better than for other fc plasmas, such as $\mathrm{CF}_{4}, \mathrm{CHF}_{3}$, and $\mathrm{C}_{2} \mathrm{~F}_{6} \cdot{ }^{5-7}$ Besides, in combination with the strong etching gas $\mathrm{SF}_{6}$ (which is rich in $\mathrm{F}$ atoms), $\mathrm{C}_{4} \mathrm{~F}_{8}$ is also widely used for the Bosch process, ${ }^{8,9}$ which is the stateof-the-art procedure for high aspect ratio (AR) Si etching in micro electromechanical systems (MEMSs). ${ }^{10,11}$

Due to its widespread applications, it is vital to investigate the $\mathrm{C}_{4} \mathrm{~F}_{8}$ plasma properties, i.e., the behavior of the various ions and radicals, with special attention to the chemical-etching and polymerization oriented species, i.e., the $\mathrm{F} / \mathrm{C}_{\mathrm{x}} \mathrm{F}_{\mathrm{y}}$ ratio. Indeed, the latter can microscopically influence the feature profile characteristics along the wafer surface and hence determine the etch quality, ${ }^{12-18}$ such as the etch speed, selectivity, anisotropy, AR and critical dimension (CD), the surface roughness, and the degree of implantation and mixing.

A lot of experimental work has been conducted for a better understanding of the $\mathrm{C}_{4} \mathrm{~F}_{8}$ plasma itself, as well as for the formation of the polymerization film and the etch mechanism, focusing among others on the non-Maxwellian electron energy distribution function (EEDF) ${ }^{19}$ the spatial characteristics of the $\mathrm{CF}$ and $\mathrm{CF}_{2}$ radicals, ${ }^{20}$ the dissociation mechanism of $\mathrm{C}_{4} \mathrm{~F}_{8},{ }^{21,22}$ the role of heavy and light radicals in the etching and the film deposition, ${ }^{23}$ and the precursor species for fluorocarbon film growth. ${ }^{24}$ Moreover, some simulation work was also carried out to study the properties of magnetically confined $\mathrm{C}_{4} \mathrm{~F}_{8}$ plasmas ${ }^{25,26}$ and the effect of the fluorocarbon film on the bulk plasma. ${ }^{27}$

It is known that the dissociation and ionization characteristics of $\mathrm{C}_{4} \mathrm{~F}_{8}$-based plasmas at various discharge conditions can be quite different, since plenty of combinations for the fragmentation of this molecule exist. Many attempts have been made in the literature, aiming to reveal the fragmentation mechanisms. ${ }^{28-34}$ However, the above studies were not systematic, and they solely focused on certain species, i.e., only the light species, ${ }^{28-32}$ or the heavy or polymeric species, ${ }^{33}$ or they dealt only with $\mathrm{F}$ and $\mathrm{CF}_{2}$, which are recognized as the main etching and polymerization related species. ${ }^{34}$ To our knowledge, a systematic study about the entire dissociation and ionization mechanism of $\mathrm{C}_{4} \mathrm{~F}_{8}$ plasmas, including all different types of ions and neutrals, is not yet reported. It is, however, very important, since earlier work revealed that the light (i.e., $\mathrm{F}$ and $\mathrm{CF}_{\mathrm{x}}$ neutrals, and $\mathrm{CF}_{\mathrm{x}}{ }^{+}$ions) and heavy or polymeric species (i.e., $\mathrm{C}_{2} \mathrm{~F}_{4}$, $\mathrm{C}_{3} \mathrm{~F}_{5}{ }^{+}$, etc.) may play a synergic role for certain aspects of the etch process, such as polymerization, chemical etching, and physical sputtering. ${ }^{35-40}$

Therefore, in this paper, we study in detail the dissociation and ionization mechanisms of a $\mathrm{C}_{4} \mathrm{~F}_{8}$ inductively coupled plasma (ICP) in a wide range of discharge conditions, focusing on the fragmentation structure, i.e., the total 
(a) Dissociation

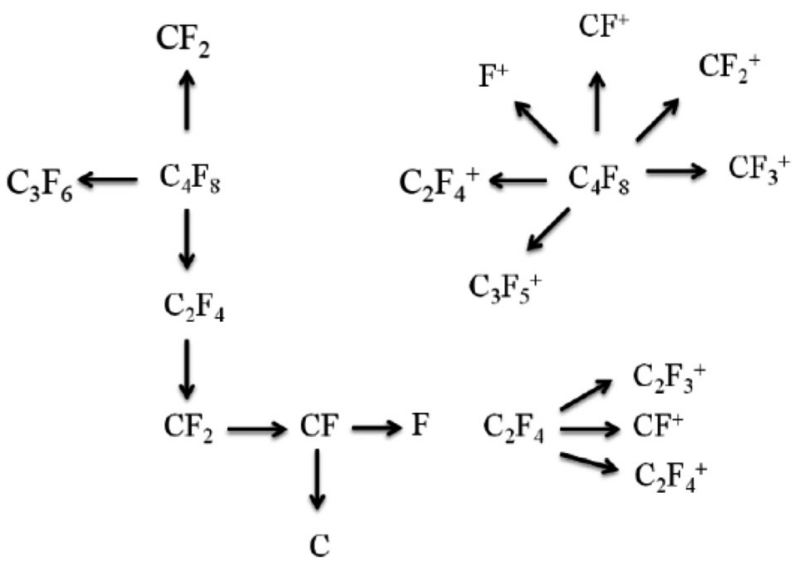

dissociation degree, the density ratios of ions vs. neutrals and of $\mathrm{F}$ vs. $\mathrm{C}_{\mathrm{x}} \mathrm{F}_{\mathrm{y}}$, and the fractions of various fc neutrals and ions. The structure of the paper is as follows. In Sec. II, the model description is given. In Sec. III, the results are divided into four parts. The first part is about the dissociation degree, and the specific density ratios, such as $\mathrm{F}$ vs. $\mathrm{C}_{\mathrm{x}} \mathrm{F}_{\mathrm{y}}$, and all fc neutrals vs. all fc ions. In the second part, the global fragmentation of the $\mathrm{C}_{4} \mathrm{~F}_{8}$ ICP at different discharge conditions is presented and discussed. The third part is about the evolution of various fc neutral and ion fractions with the discharge conditions, while in the fourth part, the validation of the model is presented and the limitations are discussed. Finally, a conclusion will be given in Sec. IV.

\section{MODEL DESCRIPTION}

We made use of the hybrid plasma equipment model (HPEM), ${ }^{41-43}$ developed by Kushner and his group. This model is widely used in low-temperature radio-frequency (rf) plasma simulations for the micro-electronics industry. The model is mainly composed of three modules, i.e., the electromagnetics module (EMM), the electron energy transport module (EETM), and the fluid kinetics module (FKM). In simulations for ICP sources, the EMM is used to solve the Maxwell equations for calculating the rf electric and magnetic fields. In the EETM, either electron Monte Carlo simulations or the Boltzmann equation can be used, according to the discharge conditions. Usually, the electron Monte Carlo simulations are preferred if the gas pressure is relatively low, i.e., in the range of $10 \mathrm{~s}$ of mTorr, while the Boltzmann equation is selected when the gas pressure is in the range of $100 \mathrm{~s}$ of mTorr. In this work, we applied the electron Monte Carlo module, since the gas pressure for polymerization and etching is typically below 100 mTorr. The FKM includes a set of fluid equations, i.e., mass and momentum continuity equations, from which the densities of the various charged and neutral plasma species are calculated. Besides, it contains the Poisson equation, to calculate the static-electric field. The three modules are iterated with each other until a final steady state is reached. This is defined when the relative changes in the densities of all considered species between two successive iterations are less than $10^{-4}$. (c) Attachment

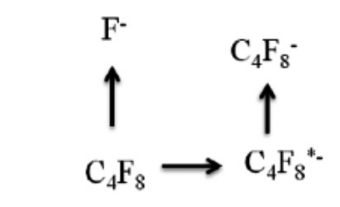

FIG. 1. Schematic picture of the electron-impact reactions occurring in a $\mathrm{C}_{4} \mathrm{~F}_{8}$ plasma: (a) dissociation, (b) ionization, and (c) attachment, illustrating the precursor molecule and its<smiles>[14CH2][C@@H](F)C(F)(F)F</smiles>
fragmented species.
A gas-phase reaction set is built for the $\mathrm{C}_{4} \mathrm{~F}_{8}$ plasma. ${ }^{44}$ The main electron-impact reaction scheme, including dissociation, ionization, and attachment, adopted for the $\mathrm{C}_{4} \mathrm{~F}_{8}$ molecule, is given in Fig. 1. The species considered in the model are listed in Table I. These species, including radicals, molecules, and positive and negative ions, can be divided into six types, i.e., belonging to $\mathrm{C}, \mathrm{F}, \mathrm{CF}_{\mathrm{a}}, \mathrm{C}_{2} \mathrm{~F}_{\mathrm{b}}, \mathrm{C}_{3} \mathrm{~F}_{\mathrm{c}}$, and $\mathrm{C}_{4} \mathrm{~F}_{\mathrm{d}}$, with different possibilities for the subscripts $\mathrm{a}, \mathrm{b}, \mathrm{c}$, and $\mathrm{d}$. The reactions of $\mathrm{C}, \mathrm{F}, \mathrm{CF}_{\mathrm{a}}$, and $\mathrm{C}_{2} \mathrm{~F}_{\mathrm{b}}$ species with electrons, as well as the chemical reactions between these species, were already presented in our previous papers. ${ }^{45,46}$ Therefore, in the present paper, only the reactions involving the $\mathrm{C}_{3} \mathrm{~F}_{\mathrm{c}}$ and $\mathrm{C}_{4} \mathrm{~F}_{\mathrm{d}}$ species are listed in Table II. In the surface reaction set, all ions and excited neutrals are recycled back into the plasma as neutrals, after neutralization and de-excitation, respectively. The F atoms and light fc neutrals are assumed to stick on the surface with different probabilities, as explained in detail in Ref. 46. The heavy fc neutrals are all reflected from the surface into the plasma. The $\mathrm{F}$ and $\mathrm{CF}_{3}$ neutrals will recombine after sticking on the surface, and then return into the plasma as $\mathrm{F}_{2}$ and $\mathrm{C}_{2} \mathrm{~F}_{6}$ molecules, respectively. More details about the surface reaction set can be found in Refs. 45 and 46.

This surface reaction set is quite simplified. For instance, the assumption that the heavy fc neutrals are all reflected from the surface is probably too simple, as they might dissociate by impacting the surface, and some of their fragments might chemisorb on the surface. However, the aim of our paper is to focus on the bulk processes, and as will be shown below, the heavy fc neutrals have much lower densities than the light $\mathrm{CF}_{\mathrm{x}}$ species, so the above assumption

TABLE I. Species included in the model for the $\mathrm{C}_{4} \mathrm{~F}_{8}$ plasma, besides the electrons.

\begin{tabular}{lc}
\hline \hline Type & Species \\
\hline C species & $\mathrm{C}, \mathrm{C}^{+}$ \\
F species & $\mathrm{F}, \mathrm{F}^{-}, \mathrm{F}^{+}, \mathrm{F}_{2}, \mathrm{~F}_{2}{ }^{+}$ \\
$\mathrm{CF}_{\mathrm{a}}$ species & $\mathrm{CF}, \mathrm{CF}_{2}, \mathrm{CF}_{3}, \mathrm{CF}_{4}, \mathrm{CF}^{+}, \mathrm{CF}_{2}{ }^{+}, \mathrm{CF}_{3}{ }^{+}, \mathrm{CF}_{3}{ }^{-}$ \\
$\mathrm{C}_{2} \mathrm{~F}_{\mathrm{b}}$ species & $\mathrm{C}_{2} \mathrm{~F}_{3}, \mathrm{C}_{2} \mathrm{~F}_{4}, \mathrm{C}_{2} \mathrm{~F}_{5}, \mathrm{C}_{2} \mathrm{~F}_{6}, \mathrm{C}_{2} \mathrm{~F}_{3}{ }^{+}, \mathrm{C}_{2} \mathrm{~F}_{4}{ }^{+}, \mathrm{C}_{2} \mathrm{~F}_{5}{ }^{+}$ \\
$\mathrm{C}_{3} \mathrm{~F}_{\mathrm{c}}$ species & $\mathrm{C}_{3} \mathrm{~F}_{5}, \mathrm{C}_{3} \mathrm{~F}_{6}, \mathrm{C}_{3} \mathrm{~F}_{7}, \mathrm{C}_{3} \mathrm{~F}_{5}{ }^{+}, \mathrm{C}_{3} \mathrm{~F}_{6}{ }^{+}, \mathrm{C}_{3} \mathrm{~F}_{7}{ }^{+}$ \\
$\mathrm{C}_{4} \mathrm{~F}_{\mathrm{d}}$ species & $\mathrm{C}_{4} \mathrm{~F}_{8}, \mathrm{C}_{4} \mathrm{~F}_{8}{ }^{-}, \mathrm{C}_{4} \mathrm{~F}_{8}{ }^{*-}, \mathrm{C}_{4} \mathrm{~F}_{7}, \mathrm{C}_{4} \mathrm{~F}_{7}{ }^{+}$ \\
\hline \hline
\end{tabular}


TABLE II. Chemical reactions for the $\mathrm{C}_{3} \mathrm{~F}_{\mathrm{c}}$ and $\mathrm{C}_{4} \mathrm{~F}_{\mathrm{d}}$ species considered in the model, as well as the rate coefficients and the references where these data were adopted from.

\begin{tabular}{|c|c|c|c|c|c|}
\hline No. & Reaction & Rate coefficient ${ }^{\mathrm{a}}$ & Threshold (eV) & Reaction type & Reference \\
\hline 1 & $\mathrm{e}+\mathrm{C}_{3} \mathrm{~F}_{5} \rightarrow \mathrm{C}_{2} \mathrm{~F}_{3}+\mathrm{CF}_{2}+\mathrm{e}$ & $1.8 \times 10^{-8} \times \mathrm{T}_{\mathrm{e}}^{0.52} \times \exp \left(-\frac{12.3}{\mathrm{~T}_{\mathrm{e}}}\right)$ & 5.0 & Dissociation & 44 \\
\hline 2 & $\mathrm{e}+\mathrm{C}_{3} \mathrm{~F}_{5} \rightarrow \mathrm{C}_{2} \mathrm{~F}_{4}+\mathrm{CF}+\mathrm{e}$ & $1.8 \times 10^{-8} \times \mathrm{T}_{\mathrm{e}}^{0.52} \times \exp \left(-\frac{12.3}{\mathrm{~T}_{\mathrm{e}}}\right)$ & 5.0 & Dissociation & 44 \\
\hline 3 & $\mathrm{e}+\mathrm{C}_{3} \mathrm{~F}_{5}{ }^{+} \rightarrow \mathrm{C}_{2} \mathrm{~F}_{3}+\mathrm{CF}_{2}$ & $8.0 \times 10^{-8} \times \mathrm{T}_{\mathrm{e}}^{-0.5}$ & 0.0 & Dissociative recombination & 44 \\
\hline 4 & $\mathrm{e}+\mathrm{C}_{3} \mathrm{~F}_{6} \rightarrow \mathrm{C}_{3} \mathrm{~F}_{6}^{+}+\mathrm{e}+\mathrm{e}$ & $1.4 \times 10^{-8} \times \mathrm{T}_{\mathrm{e}}^{0.68} \times \exp \left(-\frac{10.6}{\mathrm{~T}_{\mathrm{e}}}\right)$ & 9.89 & Parent ionization & 44 \\
\hline 5 & $\mathrm{e}+\mathrm{C}_{3} \mathrm{~F}_{6} \rightarrow \mathrm{C}_{2} \mathrm{~F}_{3}+\mathrm{CF}_{3}+\mathrm{e}$ & $1.8 \times 10^{-8} \times \mathrm{T}_{\mathrm{e}}^{0.52} \times \exp \left(-\frac{12.3}{\mathrm{~T}_{\mathrm{e}}}\right)$ & 5.0 & Dissociation & 44 \\
\hline 6 & $\mathrm{e}+\mathrm{C}_{3} \mathrm{~F}_{6} \rightarrow \mathrm{C}_{2} \mathrm{~F}_{4}+\mathrm{CF}_{2}+\mathrm{e}$ & $1.8 \times 10^{-8} \times \mathrm{T}_{\mathrm{e}}^{0.52} \times \exp \left(-\frac{12.3}{\mathrm{~T}_{\mathrm{e}}}\right)$ & 5.0 & Dissociation & 44 \\
\hline 7 & $\mathrm{e}+\mathrm{C}_{3} \mathrm{~F}_{6}{ }^{+} \rightarrow \mathrm{C}_{2} \mathrm{~F}_{4}+\mathrm{CF}_{2}$ & $8.0 \times 10^{-8} \times \mathrm{T}_{\mathrm{e}}^{-0.5}$ & 0.0 & Dissociative recombination & 44 \\
\hline 8 & $\mathrm{e}+\mathrm{C}_{3} \mathrm{~F}_{7} \rightarrow \mathrm{C}_{2} \mathrm{~F}_{4}+\mathrm{CF}_{3}+\mathrm{e}$ & $1.8 \times 10^{-8} \times \mathrm{T}_{\mathrm{e}}^{0.52} \times \exp \left(-\frac{12.3}{\mathrm{~T}_{\mathrm{e}}}\right)$ & 5.0 & Dissociation & 44 \\
\hline 9 & $\mathrm{e}+\mathrm{C}_{3} \mathrm{~F}_{7}{ }^{+} \rightarrow \mathrm{C}_{2} \mathrm{~F}_{4}+\mathrm{CF}_{3}$ & $8.0 \times 10^{-8} \times \mathrm{T}_{\mathrm{e}}^{-0.5}$ & 0.0 & Dissociative recombination & 44 \\
\hline 10 & $\mathrm{e}+\mathrm{C}_{4} \mathrm{~F}_{7} \rightarrow \mathrm{C}_{2} \mathrm{~F}_{4}+\mathrm{C}_{2} \mathrm{~F}_{3}+\mathrm{e}$ & $5.7 \times 10^{-8} \times \mathrm{T}_{\mathrm{e}}^{0.28} \times \exp \left(-\frac{8.0}{\mathrm{~T}_{\mathrm{e}}}\right)$ & 12.3 & Dissociation & 44 \\
\hline 11 & $\mathrm{e}+\mathrm{C}_{4} \mathrm{~F}_{7} \rightarrow \mathrm{C}_{4} \mathrm{~F}_{7}++\mathrm{e}+\mathrm{e}$ & $1.4 \times 10^{-8} \times \mathrm{T}_{\mathrm{e}}^{0.68} \times \exp \left(-\frac{10.6}{\mathrm{~T}_{\mathrm{e}}}\right)$ & 14.2 & Parent ionization & 44 \\
\hline $12^{\mathrm{b}}$ & $\mathrm{e}+\mathrm{C}_{4} \mathrm{~F}_{7}^{+} \rightarrow \mathrm{C}_{2} \mathrm{~F}_{4}+\mathrm{C}_{2} \mathrm{~F}_{3}$ & $8.0 \times 10^{-8} \times \mathrm{T}_{\mathrm{e}}^{-0.5}$ & 0.0 & Dissociative recombination & 44 \\
\hline 13 & $\mathrm{e}+\mathrm{C}_{4} \mathrm{~F}_{8} \rightarrow \mathrm{C}_{4} \mathrm{~F}_{8}+\mathrm{e}$ & $\mathrm{c}$ & 0.0 & Momentum transfer & 47 \\
\hline 14 & $\mathrm{e}+\mathrm{C}_{4} \mathrm{~F}_{8} \rightarrow \mathrm{C}_{4} \mathrm{~F}_{8}(\mathrm{v} 1)+\mathrm{e}$ & $\mathrm{c}$ & 0.12 & Vibrational excitation & 47 \\
\hline 15 & $\mathrm{e}+\mathrm{C}_{4} \mathrm{~F}_{8} \rightarrow \mathrm{C}_{2} \mathrm{~F}_{4}+\mathrm{C}_{2} \mathrm{~F}_{4}+\mathrm{e}$ & $\mathrm{c}$ & 8.0 & Dissociation & 47 \\
\hline 16 & $\mathrm{e}+\mathrm{C}_{4} \mathrm{~F}_{8} \rightarrow \mathrm{C}_{4} \mathrm{~F}_{8}^{-*}$ & $\mathrm{c}$ & 0.0 & Excited parent attachment $^{\mathrm{c}}$ & 47 \\
\hline 17 & $\mathrm{e}+\mathrm{C}_{4} \mathrm{~F}_{8} \rightarrow \mathrm{F}^{-}+\mathrm{C}_{4} \mathrm{~F}_{7}$ & $\mathrm{c}$ & 3.0 & Dissociative attachment & 47 \\
\hline 18 & $\mathrm{e}+\mathrm{C}_{4} \mathrm{~F}_{8} \rightarrow \mathrm{C}_{3} \mathrm{~F}_{5}{ }^{+}+\mathrm{CF}_{3}+\mathrm{e}+\mathrm{e}$ & $\mathrm{c}$ & 11.5 & Dissociative ionization & 48 \\
\hline 19 & $\mathrm{e}+\mathrm{C}_{4} \mathrm{~F}_{8} \rightarrow \mathrm{C}_{2} \mathrm{~F}_{4}^{+}+\mathrm{C}_{2} \mathrm{~F}_{4}+\mathrm{e}+\mathrm{e}$ & $\mathrm{c}$ & 12.3 & Dissociative ionization & 48 \\
\hline 20 & $\mathrm{e}+\mathrm{C}_{4} \mathrm{~F}_{8} \rightarrow \mathrm{F}^{+}+\mathrm{C}_{4} \mathrm{~F}_{7}+\mathrm{e}+\mathrm{e}$ & $\mathrm{c}$ & 12.9 & Dissociative ionization & 48 \\
\hline 21 & $\mathrm{e}+\mathrm{C}_{4} \mathrm{~F}_{8} \rightarrow \mathrm{CF}_{3}{ }^{+}+\mathrm{C}_{3} \mathrm{~F}_{5}+\mathrm{e}+\mathrm{e}$ & $\mathrm{c}$ & 12.7 & Dissociative ionization & 48 \\
\hline 22 & $\mathrm{e}+\mathrm{C}_{4} \mathrm{~F}_{8} \rightarrow \mathrm{CF}_{2}^{+}+\mathrm{C}_{3} \mathrm{~F}_{6}+\mathrm{e}+\mathrm{e}$ & $\mathrm{c}$ & 13.4 & Dissociative ionization & 48 \\
\hline 23 & $\mathrm{e}+\mathrm{C}_{4} \mathrm{~F}_{8} \rightarrow \mathrm{CF}^{+}+\mathrm{C}_{3} \mathrm{~F}_{7}+\mathrm{e}+\mathrm{e}$ & $\mathrm{c}$ & 14.1 & Dissociative ionization & 48 \\
\hline 24 & $\mathrm{e}+\mathrm{C}_{4} \mathrm{~F}_{8} \rightarrow \mathrm{C}_{3} \mathrm{~F}_{6}+\mathrm{CF}_{2}+\mathrm{e}$ & $\mathrm{c}$ & 10.0 & Dissociation & 48 \\
\hline 25 & $\mathrm{~F}^{-}+\mathrm{C}_{3} \mathrm{~F}_{5}^{+} \rightarrow \mathrm{C}_{2} \mathrm{~F}_{4}+\mathrm{CF}_{2}$ & $8.0 \times 10^{-8}$ & 0 & Recombination & 44 \\
\hline 26 & $\mathrm{~F}^{-}+\mathrm{C}_{3} \mathrm{~F}_{6}{ }^{+} \rightarrow \mathrm{C}_{2} \mathrm{~F}_{4}+\mathrm{CF}_{3}$ & $8.0 \times 10^{-8}$ & 0 & Recombination & 44 \\
\hline 27 & $\mathrm{~F}^{-}+\mathrm{C}_{3} \mathrm{~F}_{7}^{+} \rightarrow \mathrm{C}_{2} \mathrm{~F}_{6}+\mathrm{CF}_{2}$ & $8.0 \times 10^{-8}$ & 0 & Recombination & 44 \\
\hline 28 & $\mathrm{~F}^{-}+\mathrm{C}_{4} \mathrm{~F}_{7}^{+} \rightarrow \mathrm{C}_{2} \mathrm{~F}_{5}+\mathrm{C}_{2} \mathrm{~F}_{3}$ & $8.0 \times 10^{-8}$ & 0 & Recombination & 44 \\
\hline 29 & $\mathrm{CF}_{3}^{-}+\mathrm{C}_{3} \mathrm{~F}_{5}^{+} \rightarrow \mathrm{CF}_{3}+\mathrm{C}_{3} \mathrm{~F}_{5}$ & $1.0 \times 10^{-7}$ & 0 & Recombination & 44 \\
\hline 30 & $\mathrm{CF}_{3}^{-}+\mathrm{C}_{3} \mathrm{~F}_{6}^{+} \rightarrow \mathrm{CF}_{3}+\mathrm{C}_{3} \mathrm{~F}_{6}$ & $1.0 \times 10^{-7}$ & 0 & Recombination & 44 \\
\hline 31 & $\mathrm{CF}_{3}^{-}+\mathrm{C}_{3} \mathrm{~F}_{7}^{+} \rightarrow \mathrm{CF}_{3}+\mathrm{C}_{3} \mathrm{~F}_{7}$ & $1.0 \times 10^{-7}$ & 0 & Recombination & 44 \\
\hline 32 & $\mathrm{CF}_{3}^{-}+\mathrm{C}_{4} \mathrm{~F}_{7}^{+} \rightarrow \mathrm{CF}_{3}+\mathrm{C}_{4} \mathrm{~F}_{7}$ & $1.0 \times 10^{-7}$ & 0 & Recombination & 44 \\
\hline 33 & $\mathrm{C}_{4} \mathrm{~F}_{8}{ }^{-}+\mathrm{F}^{+} \rightarrow \mathrm{C}_{4} \mathrm{~F}_{8}+\mathrm{F}$ & $2.0 \times 10^{-7}$ & 0 & Recombination & 44 \\
\hline 34 & $\mathrm{C}_{4} \mathrm{~F}_{8}{ }^{-}+\mathrm{F}_{2}^{+} \rightarrow \mathrm{C}_{4} \mathrm{~F}_{8}+\mathrm{F}_{2}$ & $1.5 \times 10^{-7}$ & 0 & Recombination & 44 \\
\hline 35 & $\mathrm{C}_{4} \mathrm{~F}_{8}{ }^{-}+\mathrm{C}^{+} \rightarrow \mathrm{C}_{4} \mathrm{~F}_{8}+\mathrm{C}$ & $3.0 \times 10^{-7}$ & 0 & Recombination & 44 \\
\hline 36 & $\mathrm{C}_{4} \mathrm{~F}_{8}^{-}+\mathrm{CF}^{+} \rightarrow \mathrm{C}_{4} \mathrm{~F}_{8}+\mathrm{CF}$ & $1.5 \times 10^{-7}$ & 0 & Recombination & 44 \\
\hline 37 & $\mathrm{C}_{4} \mathrm{~F}_{8}{ }^{-}+\mathrm{CF}_{2}{ }^{+} \rightarrow \mathrm{C}_{4} \mathrm{~F}_{8}+\mathrm{CF}_{2}$ & $1.0 \times 10^{-7}$ & 0 & Recombination & 44 \\
\hline 38 & $\mathrm{C}_{4} \mathrm{~F}_{8}^{-}+\mathrm{CF}_{3}^{+} \rightarrow \mathrm{C}_{4} \mathrm{~F}_{8}+\mathrm{CF}_{3}$ & $1.0 \times 10^{-7}$ & 0 & Recombination & 44 \\
\hline 39 & $\mathrm{C}_{4} \mathrm{~F}_{8}^{-}+\mathrm{C}_{2} \mathrm{~F}_{3}^{+} \rightarrow \mathrm{C}_{4} \mathrm{~F}_{8}+\mathrm{C}_{2} \mathrm{~F}_{3}$ & $9.0 \times 10^{-8}$ & 0 & Recombination & 44 \\
\hline 40 & $\mathrm{C}_{4} \mathrm{~F}_{8}^{-}+\mathrm{C}_{2} \mathrm{~F}_{4}^{+} \rightarrow \mathrm{C}_{4} \mathrm{~F}_{8}+\mathrm{C}_{2} \mathrm{~F}_{4}$ & $9.0 \times 10^{-8}$ & 0 & Recombination & 44 \\
\hline 41 & $\mathrm{C}_{4} \mathrm{~F}_{8}^{-}+\mathrm{C}_{2} \mathrm{~F}_{5}^{+} \rightarrow \mathrm{C}_{4} \mathrm{~F}_{8}+\mathrm{C}_{2} \mathrm{~F}_{5}$ & $9.0 \times 10^{-8}$ & 0 & Recombination & 44 \\
\hline 42 & $\mathrm{C}_{4} \mathrm{~F}_{8}^{-}+\mathrm{C}_{3} \mathrm{~F}_{5}^{+} \rightarrow \mathrm{C}_{4} \mathrm{~F}_{8}+\mathrm{C}_{3} \mathrm{~F}_{5}$ & $9.0 \times 10^{-8}$ & 0 & Recombination & 44 \\
\hline 43 & $\mathrm{C}_{4} \mathrm{~F}_{8}^{-}+\mathrm{C}_{3} \mathrm{~F}_{6}^{+} \rightarrow \mathrm{C}_{4} \mathrm{~F}_{8}+\mathrm{C}_{3} \mathrm{~F}_{6}$ & $9.0 \times 10^{-8}$ & 0 & Recombination & 44 \\
\hline 44 & $\mathrm{C}_{4} \mathrm{~F}_{8}^{-}+\mathrm{C}_{3} \mathrm{~F}_{7}^{+} \rightarrow \mathrm{C}_{4} \mathrm{~F}_{8}+\mathrm{C}_{3} \mathrm{~F}_{7}$ & $9.0 \times 10^{-8}$ & 0 & Recombination & 44 \\
\hline 45 & $\mathrm{C}_{4} \mathrm{~F}_{8}^{-}+\mathrm{C}_{4} \mathrm{~F}_{7}^{+} \rightarrow \mathrm{C}_{4} \mathrm{~F}_{8}+\mathrm{C}_{4} \mathrm{~F}_{7}$ & $9.0 \times 10^{-8}$ & 0 & Recombination & 44 \\
\hline 46 & $\mathrm{C}_{4} \mathrm{~F}_{8}{ }^{-*}+\mathrm{F}^{+} \rightarrow \mathrm{C}_{4} \mathrm{~F}_{8}+\mathrm{F}$ & $2.0 \times 10^{-7}$ & 0 & De-excitation and recombination & 44 \\
\hline 47 & $\mathrm{C}_{4} \mathrm{~F}_{8}{ }^{-*}+\mathrm{F}_{2}^{+} \rightarrow \mathrm{C}_{4} \mathrm{~F}_{8}+\mathrm{F}_{2}$ & $1.5 \times 10^{-7}$ & 0 & De-excitation and recombination & 44 \\
\hline 48 & $\mathrm{C}_{4} \mathrm{~F}_{8}^{-*}+\mathrm{C}^{+} \rightarrow \mathrm{C}_{4} \mathrm{~F}_{8}+\mathrm{C}$ & $3.0 \times 10^{-7}$ & 0 & De-excitation and recombination & 44 \\
\hline 49 & $\mathrm{C}_{4} \mathrm{~F}_{8}^{-*}+\mathrm{CF}^{+} \rightarrow \mathrm{C}_{4} \mathrm{~F}_{8}+\mathrm{CF}$ & $1.5 \times 10^{-7}$ & 0 & De-excitation and recombination & 44 \\
\hline 50 & $\mathrm{C}_{4} \mathrm{~F}_{8}^{-*}+\mathrm{CF}_{2}^{+} \rightarrow \mathrm{C}_{4} \mathrm{~F}_{8}+\mathrm{CF}_{2}$ & $1.0 \times 10^{-7}$ & 0 & De-excitation and recombination & 44 \\
\hline 51 & $\mathrm{C}_{4} \mathrm{~F}_{8}^{-*}+\mathrm{CF}_{3}^{+} \rightarrow \mathrm{C}_{4} \mathrm{~F}_{8}+\mathrm{CF}_{3}$ & $1.0 \times 10^{-7}$ & 0 & De-excitation and recombination & 44 \\
\hline
\end{tabular}


TABLE II. (Continued.)

\begin{tabular}{|c|c|c|c|c|c|}
\hline No. & Reaction & Rate coefficient ${ }^{\mathrm{a}}$ & Threshold (eV) & Reaction type & Reference \\
\hline 52 & $\mathrm{C}_{4} \mathrm{~F}_{8}{ }^{-*}+\mathrm{C}_{2} \mathrm{~F}_{3}^{+} \rightarrow \mathrm{C}_{4} \mathrm{~F}_{8}+\mathrm{C}_{2} \mathrm{~F}_{3}$ & $9.0 \times 10^{-8}$ & 0 & De-excitation and recombination & 44 \\
\hline 53 & $\mathrm{C}_{4} \mathrm{~F}_{8}^{-*}+\mathrm{C}_{2} \mathrm{~F}_{4}^{+} \rightarrow \mathrm{C}_{4} \mathrm{~F}_{8}+\mathrm{C}_{2} \mathrm{~F}_{4}$ & $9.0 \times 10^{-8}$ & 0 & De-excitation and recombination & 44 \\
\hline 54 & $\mathrm{C}_{4} \mathrm{~F}_{8}{ }^{-*}+\mathrm{C}_{2} \mathrm{~F}_{5}{ }^{+} \rightarrow \mathrm{C}_{4} \mathrm{~F}_{8}+\mathrm{C}_{2} \mathrm{~F}_{5}$ & $9.0 \times 10^{-8}$ & 0 & De-excitation and recombination & 44 \\
\hline 55 & $\mathrm{C}_{4} \mathrm{~F}_{8}{ }^{-*}+\mathrm{C}_{3} \mathrm{~F}_{5}^{+} \rightarrow \mathrm{C}_{4} \mathrm{~F}_{8}+\mathrm{C}_{3} \mathrm{~F}_{5}$ & $9.0 \times 10^{-8}$ & 0 & De-excitation and recombination & 44 \\
\hline 56 & $\mathrm{C}_{4} \mathrm{~F}_{8}{ }^{*}+\mathrm{C}_{3} \mathrm{~F}_{6}^{+} \rightarrow \mathrm{C}_{4} \mathrm{~F}_{8}+\mathrm{C}_{3} \mathrm{~F}_{6}$ & $9.0 \times 10^{-8}$ & 0 & De-excitation and recombination & 44 \\
\hline 57 & $\mathrm{C}_{4} \mathrm{~F}_{8}^{-*}+\mathrm{C}_{3} \mathrm{~F}_{7}^{+} \rightarrow \mathrm{C}_{4} \mathrm{~F}_{8}+\mathrm{C}_{3} \mathrm{~F}_{7}$ & $9.0 \times 10^{-8}$ & 0 & De-excitation and recombination & 44 \\
\hline 58 & $\mathrm{C}_{4} \mathrm{~F}_{8}^{-*}+\mathrm{C}_{4} \mathrm{~F}_{7}^{+} \rightarrow \mathrm{C}_{4} \mathrm{~F}_{8}+\mathrm{C}_{4} \mathrm{~F}_{7}$ & $9.0 \times 10^{-8}$ & 0 & De-excitation and recombination & 44 \\
\hline 59 & $\mathrm{~F}+\mathrm{C}_{4} \mathrm{~F}_{7} \rightarrow \mathrm{C}_{2} \mathrm{~F}_{4}+\mathrm{C}_{2} \mathrm{~F}_{4}$ & $1.0 \times 10^{-11}$ & 0 & Atom exchange & 44 \\
\hline 60 & $\mathrm{~F}+\mathrm{C}_{3} \mathrm{~F}_{6} \rightarrow \mathrm{C}_{3} \mathrm{~F}_{7}$ & $1.0 \times 10^{-12}$ & 0 & Recombination & 44 \\
\hline 61 & $\mathrm{~F}_{2}+\mathrm{C}_{3} \mathrm{~F}_{6} \rightarrow \mathrm{C}_{3} \mathrm{~F}_{7}+\mathrm{F}$ & $3.5 \times 10^{-16}$ & 0 & Atom exchange & 44 \\
\hline 62 & $\mathrm{CF}_{3}{ }^{+}+\mathrm{C}_{3} \mathrm{~F}_{5} \rightarrow \mathrm{C}_{3} \mathrm{~F}_{5}{ }^{+}+\mathrm{CF}_{3}$ & $7.04 \times 10^{-10}$ & 0 & Charge exchange & 44 \\
\hline 63 & $\mathrm{CF}_{3}{ }^{+}+\mathrm{C}_{3} \mathrm{~F}_{7} \rightarrow \mathrm{C}_{3} \mathrm{~F}_{7}{ }^{+}+\mathrm{CF}_{3}$ & $7.04 \times 10^{-10}$ & 0 & Charge exchange & 44 \\
\hline 64 & $\mathrm{C}_{4} \mathrm{~F}_{8}^{-}+\mathrm{F} \rightarrow \mathrm{C}_{4} \mathrm{~F}_{8}+\mathrm{F}^{-}$ & $1.0 \times 10^{-9}$ & 0 & Charge exchange & 44 \\
\hline 65 & $\mathrm{C}_{4} \mathrm{~F}_{8}^{-*}+\mathrm{M} \rightarrow \mathrm{C}_{4} \mathrm{~F}_{8}^{-}+\mathrm{M}$ & $1.0 \times 10^{-10}$ & 0 & De-excitation $^{\mathrm{c}}$ & 44 \\
\hline 66 & $\mathrm{C}_{4} \mathrm{~F}_{8}{ }^{*} \rightarrow \mathrm{C}_{4} \mathrm{~F}_{8}+\mathrm{e}$ & $1.0 \times 10^{5}$ & 0 & Autodetachment ${ }^{\mathrm{d}}$ & 44 \\
\hline 67 & $\mathrm{C}_{3} \mathrm{~F}_{5}^{+}+\mathrm{C}_{3} \mathrm{~F}_{5} \rightarrow \mathrm{C}_{3} \mathrm{~F}_{5}+\mathrm{C}_{3} \mathrm{~F}_{5}^{+}$ & $3.0 \times 10^{-9}$ & 0 & Charge exchange $^{e}$ & 44 \\
\hline 68 & $\mathrm{C}_{3} \mathrm{~F}_{7}+\mathrm{C}_{3} \mathrm{~F}_{7} \rightarrow \mathrm{C}_{3} \mathrm{~F}_{7}+\mathrm{C}_{3} \mathrm{~F}_{7}^{+}$ & $3.0 \times 10^{-9}$ & 0 & Charge exchange $e^{e}$ & 44 \\
\hline 69 & $\mathrm{C}_{3} \mathrm{~F}_{7}^{+}+\mathrm{C}_{2} \mathrm{~F}_{4} \rightarrow \mathrm{C}_{4} \mathrm{~F}_{8}+\mathrm{CF}_{3}^{+}$ & $2.0 \times 10^{-11}$ & 0 & Charge and atom exchange & 44 \\
\hline
\end{tabular}

${ }^{a}$ The unit of the rate coefficient is $\mathrm{cm}^{3} \mathrm{~s}^{-1}$ for the two-body reactions. The letter $\mathrm{c}$ means that the rate coefficient is calculated from the electron energy transport module based on the corresponding electron impact cross sections.

${ }^{\mathrm{b}}$ The rate coefficients of the first 12 reactions are obtained from a Maxwellian EEDF, whereas in reality the EEDF deviates from a Maxwellian distribution (see Figure 7 below), but this approximation does not affect the results, as these reactions are of minor importance, except for reaction 11 (see Tables IV and V below).

${ }^{\mathrm{c}}$ According to experiments, ${ }^{49}$ the parent or non-dissociative attachment of low energy electrons with $\mathrm{C}_{4} \mathrm{~F}_{8}$ proceeds in two steps, i.e., first formation of excited negative ions $\left(\mathrm{C}_{4} \mathrm{~F}_{8}{ }^{-*}\right.$, for which the internal excitation energy is larger than the electron affinity), followed by relaxation to ground state $\mathrm{C}_{4} \mathrm{~F}_{8}{ }^{-}$by collision with heavy neutral species. These two steps are represented in our reaction set by Nos. 16 and 65 , respectively.

${ }^{\mathrm{d}}$ The lifetime of $\mathrm{C}_{4} \mathrm{~F}_{8}{ }^{-*}$ for autodetachment was measured as $10 \mu$ s using time-of-flight mass spectrometry. ${ }^{50}$ Thus, we estimated the rate coefficient of this process as $10^{5} \mathrm{~s}^{-1}$.

${ }^{\mathrm{e}}$ The charge exchange reactions (i.e., reactions 67 and 68 ) do not change the density of the reacting species, but only their momentum and energy.

will probably not have a large effect on our results. Nevertheless, it is important to realize that the simplified surface reaction set might affect the simulation results to some extent, as will be elaborated in Sec. III D below.

A schematic diagram of the ICP reactor considered in this work is given in Fig. 2. The height and radius of the

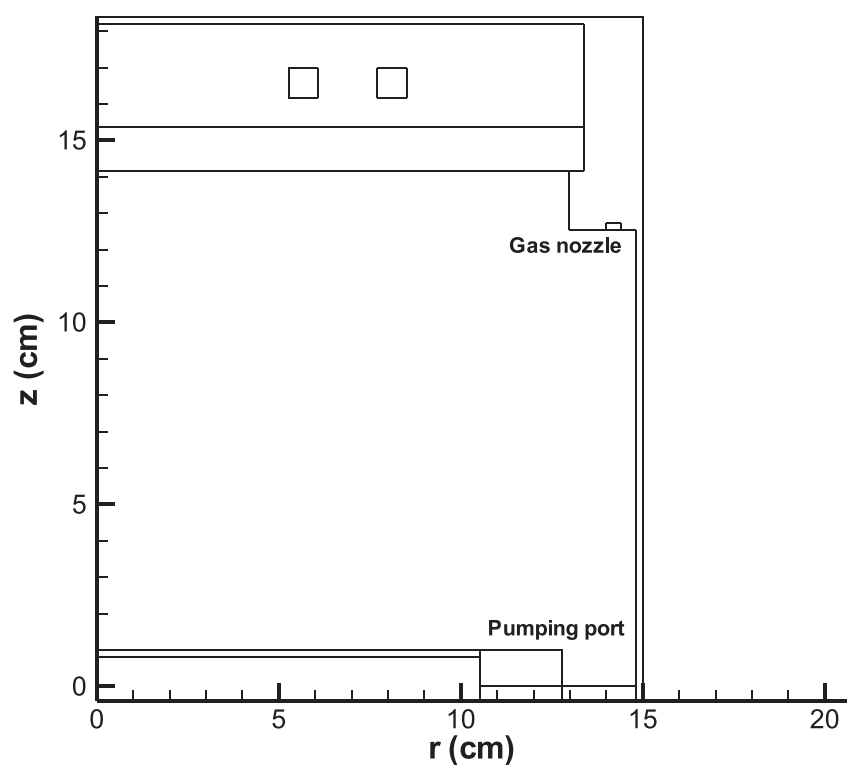

FIG. 2. Schematic picture of the ICP reactor assumed in the model. It is cylindrically symmetrical around the symmetry axis $r=0$. chamber are both $15 \mathrm{~cm}$. A two-turn coil is powered by a 13.56 MHz current source. The $\mathrm{C}_{4} \mathrm{~F}_{8}$ gas is introduced into the chamber by the nozzle along the edge ring near the sidewall, and pumped out of the chamber through the pumping port at the edge bottom of the chamber. The substrate is clamped by a dielectric ring at the bottom of the chamber. No bias power is applied onto the substrate, since we focus only on the bulk plasma properties in this work. The gas pressure is set in the range of 5-50mTorr and the coil power in the range of 100-900 W.

\section{RESULTS AND DISCUSSION}

The entire fragmentation scheme, as defined in our work, includes the dissociation, ionization, and attachment channels, as shown in Fig. 1. Therefore, three types of species are generated, i.e., neutrals, positive and negative ions, as listed in Table I. In this work, however, we focus on the species involved in the etching process, i.e., fc neutrals and impinging positive ions. Indeed, the negative ions are always restricted to the bulk plasma by the sheath potential in front of the walls, so they cannot pass through the sheath to participate in the surface kinetics.

For the sake of clarity, the fc positive ions are lumped into four types, i.e., $\mathrm{CF} \alpha^{+}, \mathrm{C}_{2} \mathrm{~F}_{\beta}^{+}, \mathrm{C}_{3} \mathrm{~F}_{\gamma}^{+}$, and $\mathrm{C}_{4} \mathrm{~F}_{7}^{+}$, besides the $\mathrm{C}^{+}, \mathrm{F}^{+}$, and $\mathrm{F}_{2}^{+}$ions. The latter three ions are calculated to have pretty low densities in our simulations, i.e., around $10^{5}-10^{8} \mathrm{~cm}^{-3}$, which is several orders lower than for the other ions, and thus they are neglected. Similarly, the fc 
neutrals are lumped into seven types, i.e., $\mathrm{CF}_{\mathrm{x}}, \mathrm{C}_{2} \mathrm{~F}_{\mathrm{y}}, \mathrm{C}_{3} \mathrm{~F}_{\mathrm{z}}$, $\mathrm{C}_{4} \mathrm{~F}_{7}, \mathrm{C}, \mathrm{F}$, and $\mathrm{F}_{2}$. Indeed, in Refs. 21 and 22, the heavy fc species with $\mathrm{C}_{4}$ component are mainly represented by $\mathrm{C}_{4} \mathrm{~F}_{7}$ and $\mathrm{C}_{4} \mathrm{~F}_{7}^{+}$, so we do the same in the present work.

\section{A. Dissociation degree and specific density ratios}

In this section, the dissociation degree of $\mathrm{C}_{4} \mathrm{~F}_{8}$ and the density ratios of $\mathrm{F}$ vs. $\mathrm{C}_{\mathrm{x}} \mathrm{F}_{\mathrm{y}}$, as well as of all neutrals vs. all ions, will be presented in a range of gas pressures and coil powers. The dissociation degree is defined here as the density ratio of all the neutral dissociation products, i.e., $\mathrm{CF}_{\mathrm{x}}, \mathrm{C}_{2} \mathrm{~F}_{\mathrm{y}}, \mathrm{C}_{3} \mathrm{~F}_{\mathrm{z}}, \mathrm{C}_{4} \mathrm{~F}_{7}, \mathrm{C}, \mathrm{F}$, and $\mathrm{F}_{2}$, to the sum of all these neutral dissociation products and the parent molecule $\mathrm{C}_{4} \mathrm{~F}_{8}$. In the density ratio of neutrals vs. ions, the neutrals include $\mathrm{CF}_{\mathrm{x}}, \mathrm{C}_{2} \mathrm{~F}_{\mathrm{y}}, \mathrm{C}_{3} \mathrm{~F}_{\mathrm{z}}, \mathrm{C}_{4} \mathrm{~F}_{7}, \mathrm{C}, \mathrm{F}$, and $\mathrm{F}_{2}$ species, and the ions include $\mathrm{CF}_{\alpha}{ }^{+}, \mathrm{C}_{2} \mathrm{~F}_{\beta}^{+}, \mathrm{C}_{3} \mathrm{~F}_{\gamma}^{+}$, and $\mathrm{C}_{4} \mathrm{~F}_{7}^{+}$species. The contribution of dissociative ionization products is not taken into account here since the fc ion densities are usually several orders lower than the neutral densities. This information is needed for optimizing the $\mathrm{C}_{4} \mathrm{~F}_{8}$-plasma based process, which is based on a balance between fc film formation and etching.
The effects of gas pressure and coil power on the dissociation degree and on the density ratios of $\mathrm{F}$ vs. $\mathrm{C}_{\mathrm{x}} \mathrm{F}_{\mathrm{y}}$ species and of neutrals vs. ions are presented in Fig. 3. In Figs. 3(a)-3(c), the gas pressure effect is illustrated, for a fixed coil power of $500 \mathrm{~W}$. It can be seen from Fig. 3(a) that the dissociation degree of $\mathrm{C}_{4} \mathrm{~F}_{8}$ decreases significantly with rising gas pressure, from 0.77 at $5 \mathrm{~m}$ Torr to 0.17 at $50 \mathrm{mTorr}$. Hence, in the low pressure range, the largest fraction of $\mathrm{C}_{4} \mathrm{~F}_{8}$ is dissociated into various components, whereas at high pressure, the majority of $\mathrm{C}_{4} \mathrm{~F}_{8}$ is still present as parent molecule. This effect of pressure on the dissociation degree correlates well with the experiments of Wang et al., ${ }^{51}$ although it was measured for another gas mixture, i.e., $\mathrm{Ar} / \mathrm{O}_{2}$. We did not find literature data for a $\mathrm{C}_{4} \mathrm{~F}_{8}$ plasma.

The density ratio of $\mathrm{F}$ vs. $\mathrm{C}_{\mathrm{x}} \mathrm{F}_{\mathrm{y}}$ also drops upon rising gas pressure, i.e., from $1.8 \times 10^{-2}$ at 5 mTorr to $1.2 \times 10^{-3}$ at 50 mTorr, as can be observed from Fig. 3(b). Thus, at high pressure, the $\mathrm{C}_{4} \mathrm{~F}_{8}$ plasma contains a larger fraction of fc reactive species compared to $\mathrm{F}$ etchants. This indicates that if, during the Bosch process, the fc film polymerization on the feature profile wall would not be sufficient within the $\mathrm{C}_{4} \mathrm{~F}_{8}$ polymerization step and a notch etching would happen within the $\mathrm{SF}_{6}$ etching step, an increase of the pressure might
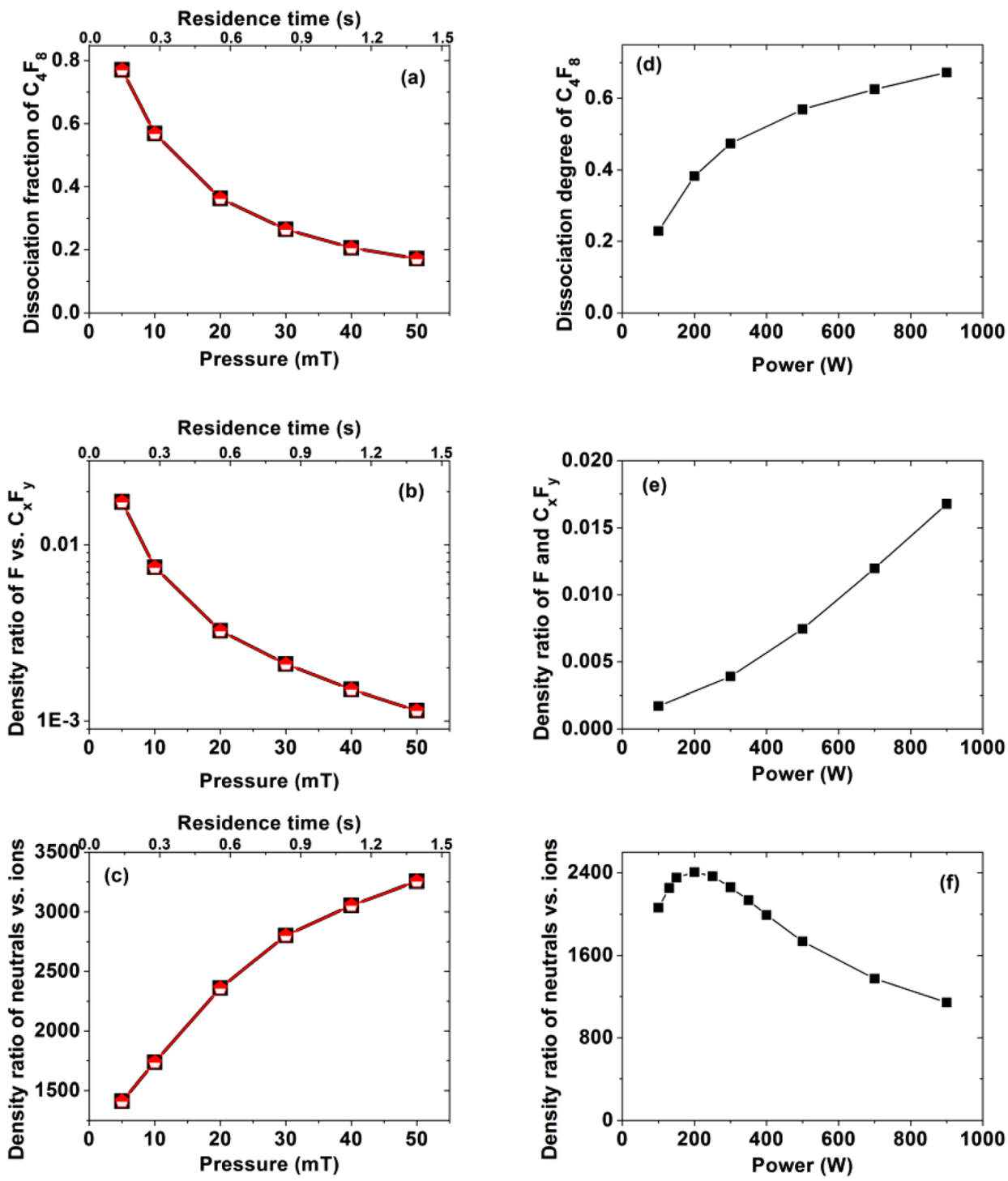

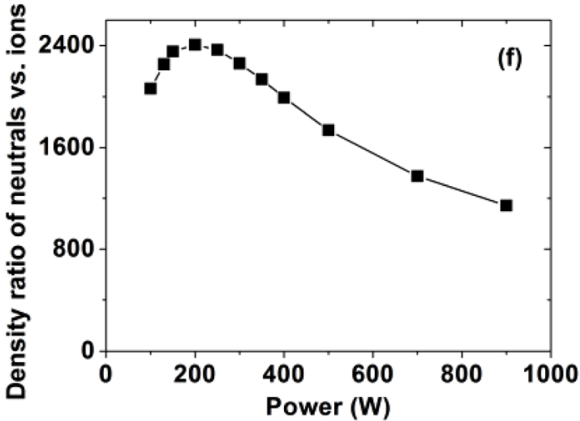

FIG. 3. Dissociation degree of $\mathrm{C}_{4} \mathrm{~F}_{8}$ (a), density ratio of $\mathrm{F}$ versus $\mathrm{C}_{\mathrm{x}} \mathrm{F}_{\mathrm{y}}$ (b), and density ratio of neutrals versus ions (c) as a function of pressure (lower $\mathrm{x}$-axis) and residence time (upper $\mathrm{x}$-axis), for a fixed coil power of $500 \mathrm{~W}$. Note that the residence time is indeed proportional to the pressure, as indicated with Eq. (1) (see text). Dissociation degree of $\mathrm{C}_{4} \mathrm{~F}_{8}$ (d), density ratio of $F$ versus $C_{x} F_{y}(e)$, and density ratio of neutrals versus ions (f) as a function of coil power, for a fixed gas pressure of $10 \mathrm{mTorr}$. The frequency of the power source is 13.56 $\mathrm{MHz}$, and the gas flow rate is $30 \mathrm{sccm}$. 
be a way to solve this problem. This conclusion correlates well with Ref. 52, where a notch etching profile, i.e., with a negative slope of the sidewall, indeed turned into a perfectly vertical and anisotropic trench, upon increasing the pressure from 10 mTorr to 25 mTorr.

In Fig. 3(c), the neutral vs. ion density ratio increases monotonically with gas pressure, i.e., from 1400 to 3300 . This can be explained by the lower electron temperature at high pressure, which is more suitable for dissociation than for ionization reactions, since they usually have a lower energy threshold; see Table II. It can thus be concluded that if the etch process is in a so-called ion-starving stage (i.e., depletion of ions) and we want to promote the ion flux compared to the neutral flux, ${ }^{53}$ a drop in pressure might be a good tuning step.

Note that Figs. 3(a)-3(c) also show the dependences of the dissociation degree, the density ratios of $\mathrm{F}$ vs. $\mathrm{C}_{\mathrm{x}} \mathrm{F}_{\mathrm{y}}$, and the density ratios of all $\mathrm{fc}$ neutrals vs. all ions against the residence time (upper $x$-axis). The residence time is calculated by $\tau_{\mathrm{r}}=\frac{\mathrm{pV}}{\mathrm{p}_{\text {atm } \mathrm{Q}}}$ (Eq. (3) of Ref. 54), where $\mathrm{p}$ is the gas pressure in units of $\mathrm{Pa}, \mathrm{V}$ is the plasma volume in units of $\mathrm{ml}$, and $\mathrm{Q}$ is the gas flow rate in units of standard cubic centimeter per minute $(\mathrm{sccm})$. Furthermore, because the gas flow rate is defined at standard conditions, i.e., $273 \mathrm{~K}$ and $101.325 \mathrm{kPa}$, $\mathrm{p}_{\mathrm{atm}}$ (atmospheric pressure) is included in the formula, to account for the difference between the reactor gas pressure and the atmospheric pressure at the gas inlet. As shown by this equation, the residence time is proportional to the pressure. Thus, the variations of the dissociation degree and of the density ratios as a function of residence time coincide with the variations as a function of the pressure.

The effect of applied power on the dissociation degree of $\mathrm{C}_{4} \mathrm{~F}_{8}$ and on the density ratios of $F$ vs. $\mathrm{C}_{\mathrm{x}} \mathrm{F}_{\mathrm{y}}$ and of neutrals vs. ions is presented in Figs. 3(d)-3(f), at a fixed pressure of 10 mTorr. As seen from Fig. 3(d), the dissociation degree increases with power, from 0.23 at $100 \mathrm{~W}$ to 0.67 at $900 \mathrm{~W}$. A similar behavior was also observed in the experiments of Nakagawa et al., ${ }^{55}$ both for a VHF and an RF ICP $\mathrm{Ar} / \mathrm{C}_{4} \mathrm{~F}_{8}$ plasma. This is logical because a high power leads to a higher electron density $n_{e}$ (see further in Fig. 6(b)), and hence to more dissociation collisions.

Furthermore, the density ratio of $F$ vs. $\mathrm{C}_{\mathrm{x}} \mathrm{F}_{\mathrm{y}}$ increases more or less linearly upon increasing power, by about one order of magnitude, i.e., from $1.7 \times 10^{-3}$ to $1.7 \times 10^{-2}$, as seen from Fig. 3(e). Hence, the $\mathrm{C}_{4} \mathrm{~F}_{8}$ molecules are mainly dissociated into fc neutrals, i.e., $\mathrm{C}_{\mathrm{x}} \mathrm{F}_{\mathrm{y}}$, and less into $\mathrm{F}$ radicals. This will also be clear from Sec. III B below. Indeed, the chemical reaction mechanism of the $\mathrm{C}_{4} \mathrm{~F}_{8}$ plasma is rather special, as most of the dissociations and dissociative ionizations of $\mathrm{C}_{4} \mathrm{~F}_{8}$ do not produce $\mathrm{F}$ atoms; see Table II. This explains the relatively low $\mathrm{F}$ density and the fact that the $\mathrm{F}$ vs. $\mathrm{C}_{\mathrm{x}} \mathrm{F}_{\mathrm{y}}$ ratio is always much lower than one in such $\mathrm{fc}$ plasma sources. $^{21,55}$ Besides, the calculated value of $F$ vs. $\mathrm{C}_{\mathrm{x}} \mathrm{F}_{\mathrm{y}}$ density ratio is generally in the same order as the reciprocal of the measured $\mathrm{CF}_{\mathrm{x}(\mathrm{x}=1-3)} / \mathrm{F}$ density ratio in Ref. 55, i.e., $10^{-2}$. The higher $\mathrm{F}$ vs. $\mathrm{C}_{\mathrm{x}} \mathrm{F}_{\mathrm{y}}$ density ratio upon increasing power can be explained by the dissociation and dissociative ionization reactions of fragmented $\mathrm{C}_{\mathrm{x}} \mathrm{F}_{\mathrm{y}}$ neutrals (see Table IV in Sec. III B below), which become gradually more important at higher power. The larger $F$ vs. $\mathrm{C}_{\mathrm{x}} \mathrm{F}_{\mathrm{y}}$ density ratio at higher applied power is again in agreement with the experiments of Nakagawa et al., ${ }^{55}$ which focused on the $\mathrm{CF}_{\mathrm{x}(\mathrm{x}=1-3)} / \mathrm{F}$ density ratio, and the latter was indeed lower at higher ICP power.

The density ratio of all neutrals vs. all ions is plotted as a function of applied power in Fig. 3(f). The density ratio first increases and then decreases upon increasing power. The density ratio lies between 1100 and 2400 in the investigated power range. As seen from Table II, the energy thresholds for ionization and dissociative ionization are always larger than for pure dissociation, and therefore a higher applied power is more suitable for ion production due to the higher electron temperature. This explains the decreasing trend in the density ratio of neutrals vs. ions in the higher power range of 200-900 W. However, in the low power range, i.e., $100-200 \mathrm{~W}$, the density ratio increases with power, because at such low power the energy is so low that the dissociation collisions still dominate the discharge, and become more important at higher energy, whereas the ionization processes do not yet play an important role.

Table III lists the total neutral and ion densities at the basic case, i.e., $500 \mathrm{~W}$ and $10 \mathrm{mTorr}$, a higher pressure case, i.e., $500 \mathrm{~W}$ and $50 \mathrm{mTorr}$, and a high power case, i.e., $900 \mathrm{~W}$ and 10 Torr. When the gas pressure increases, the total neutral density increases, but the total ion density decreases slightly. On the other hand, at increasing coil power, the total neutral density remains unchanged, while the ion density increases strikingly. Thus, a higher pressure results in more neutrals, while a higher power leads to more ions, as expected.

The fact that the total fc neutral density does not change with power might be at first sight unexpected, because the gas temperature generally rises with power. However, our neutral gas temperature simulation shows that the maximum temperature is located above the wafer, while the region under the dielectric window, where most ionization and dissociation occurs, is characterized by nearly room temperature and thus no significant heating in the entire power range investigated. Hence, the gas temperature in the discharge region responsible for most ionization and dissociation collisions does not affect the fc neutral densities. In fact, the constant total fc neutral density as a function of power is very similar to the work of Kokkoris et al. ${ }^{27}$ where both the measured and simulated (with a global model) pressure rise after the $\mathrm{C}_{4} \mathrm{~F}_{8}$ discharge ignition, caused by the appearance of a substantial number of dissociated fc neutrals, first increases with power but then saturates. The saturation of the

TABLE III. Comparison of total neutral and ion densities for three different conditions of coil power and pressure.

\begin{tabular}{lcc}
\hline \hline & $\begin{array}{c}\text { Total neutral } \\
\text { density }\left(\mathrm{cm}^{-3}\right)\end{array}$ & $\begin{array}{c}\text { Total ion } \\
\text { density }\left(\mathrm{cm}^{-3}\right)\end{array}$ \\
\hline Basic case (500 W and 10 mTorr) & $1.3 \times 10^{14}$ & $7.8 \times 10^{10}$ \\
Higher pressure (500 W and 50 mTorr) & $2.2 \times 10^{14}$ & $6.9 \times 10^{10}$ \\
Higher power (900 W and 10 mTorr) & $1.3 \times 10^{14}$ & $1.1 \times 10^{11}$ \\
\hline
\end{tabular}


fc neutral concentration with power, as predicted by our model, is caused by the fact that the feedstock $\mathrm{C}_{4} \mathrm{~F}_{8}$ molecules in the heating region (under the dielectric) are already severely depleted and the discharge is sustained by the fragmented fc neutrals. Hence, dissociation of $\mathrm{C}_{4} \mathrm{~F}_{8}$ becomes of minor importance, and cannot affect the total fc neutral density at rising power. On the other hand, the ionization degree in this power range is still so low, i.e., less than $10^{-3}$ as illustrated in Figs. 4(e) and 4(f) and Figs. 3(e) and 3(f) that the consumption of fc neutrals is also very limited. Thus, at high enough power, the fc neutral concentration will not be affected by the power, neither due to creation (by dissociation of $\mathrm{C}_{4} \mathrm{~F}_{8}$ ) nor due to loss (by electron impact ionization.

However, at relatively low powers, i.e., less than $500 \mathrm{~W}$, the total fc neutral density does increase with power, i.e., from $6.8 \times 10^{13}$ to $1.3 \times 10^{14} \mathrm{~cm}^{-3}$ when the power increases from $100 \mathrm{~W}$ to $500 \mathrm{~W}$. This is because in this low power range, the feedstock $\mathrm{C}_{4} \mathrm{~F}_{8}$ molecules are not too much depleted yet in the heating region, and the discharge is still sustained by the $\mathrm{C}_{4} \mathrm{~F}_{8}$ feedstock gas, and consequently, a higher power gives rise to more dissociation collisions, and thus the creation of a large number of fragmented fc neutral species, therefore increasing the total neutral density.
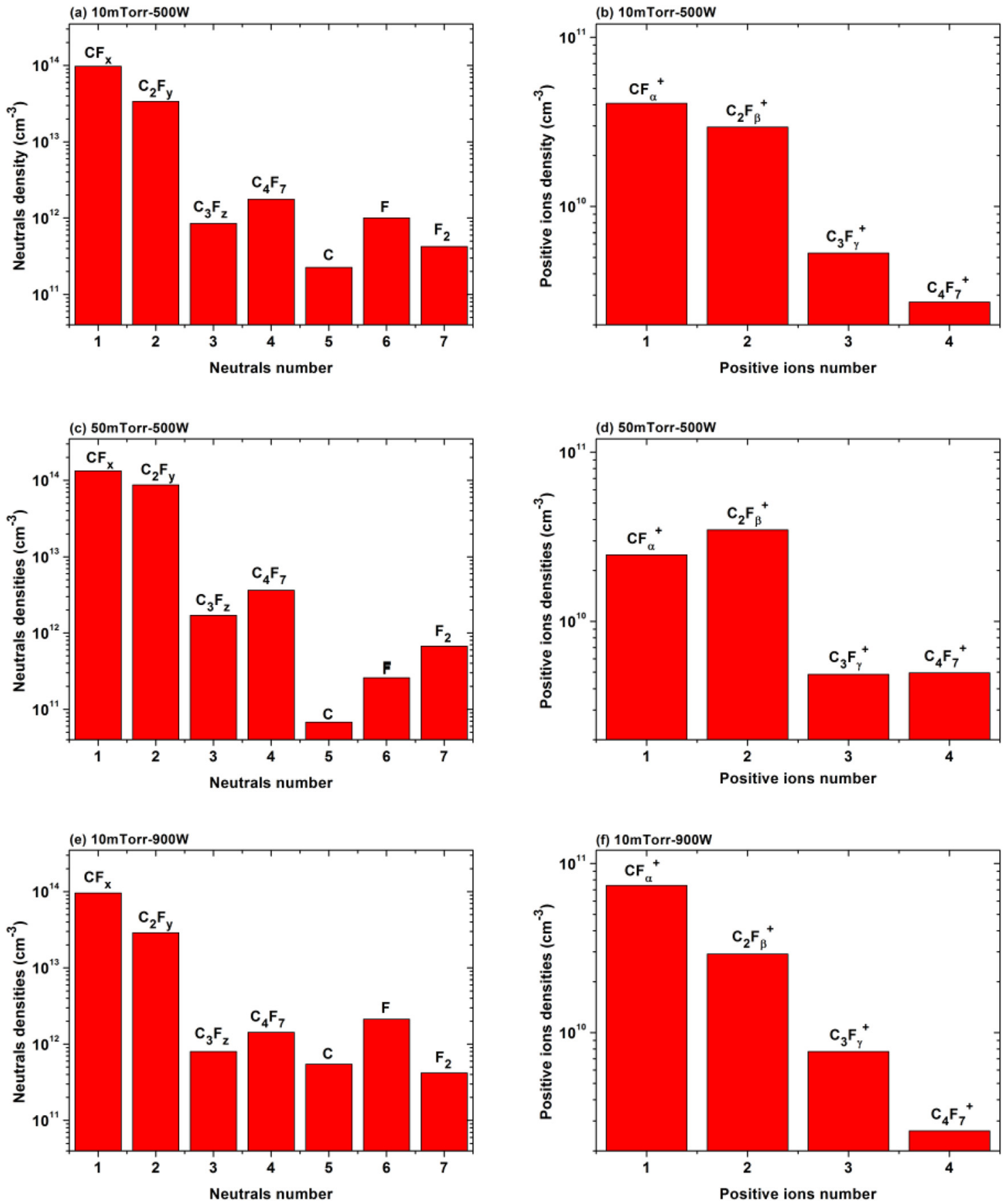

FIG. 4. Calculated densities of various neutrals (a), (c), (e), and various positive ions (b), (d), (f), averaged over the reactor geometry. The frequency of the power source is $13.56 \mathrm{MHz}$, and the gas flow rate is $30 \mathrm{sccm}$. The coil power and gas pressure are varied, as indicated in the figures. 


\section{B. Fragmentation pattern}

The fragmentation of the $\mathrm{C}_{4} \mathrm{~F}_{8}$ plasma, for different values of gas pressure and coil power, is illustrated in Fig. 4. The coil power source frequency is $13.56 \mathrm{MHz}$ and the $\mathrm{C}_{4} \mathrm{~F}_{8}$ gas flow rate is fixed at $30 \mathrm{sccm}$. As shown in Fig. 4(a), at $500 \mathrm{~W}$ and $10 \mathrm{mTorr}$, which are typical working conditions for $\mathrm{Si}$ etching, the lighter radicals, i.e., $\mathrm{CF}_{\mathrm{x}}$ and $\mathrm{C}_{2} \mathrm{~F}_{\mathrm{y}}$, are the most important neutral species. The density of the $\mathrm{CF}_{\mathrm{x}}$ radicals is almost $10^{14} \mathrm{~cm}^{-3}$, which is about three times the $\mathrm{C}_{2} \mathrm{~F}_{\mathrm{y}}$ density. The other neutral species densities are about two orders of magnitude lower, and follow the order $\mathrm{C}_{4} \mathrm{~F}_{7}>\mathrm{C}_{3} \mathrm{~F}_{\mathrm{z}}>\mathrm{F}_{2}>\mathrm{F}>\mathrm{C}$. As for the ions, it is clear from Fig. 4(b) that the lighter ions, i.e., $\mathrm{CF}_{\alpha}^{+}$and $\mathrm{C}_{2} \mathrm{~F}_{\beta}^{+}$, are also clearly dominant at these conditions and the ion densities follow the order of $\mathrm{CF}_{\alpha}^{+}>\mathrm{C}_{2} \mathrm{~F}_{\beta}^{+}>\mathrm{C}_{3} \mathrm{~F}_{\gamma}^{+}>\mathrm{C}_{4} \mathrm{~F}_{7}^{+}$. This order of the fc ion densities is in agreement with the experiments of Li et al. ${ }^{25}$ where similar discharge conditions were used, i.e., $6 \mathrm{~m}$ Torr and $600 \mathrm{~W}$.

When increasing the pressure to 50 mTorr, as shown in Fig. 4(c), the densities of all $\mathrm{C}_{\mathrm{x}} \mathrm{F}_{\mathrm{y}}$ neutrals, i.e., $\mathrm{CF}_{\mathrm{x}}, \mathrm{C}_{2} \mathrm{~F}_{\mathrm{y}}$, $\mathrm{C}_{3} \mathrm{~F}_{\mathrm{z}}$, and $\mathrm{C}_{4} \mathrm{~F}_{7}$, rise, as expected. However, the increase of the $\mathrm{CF}_{\mathrm{x}}$ density is less pronounced (i.e., only 36\%) than for the other $\mathrm{C}_{\mathrm{x}} \mathrm{F}_{\mathrm{y}}$ neutrals, especially for $\mathrm{C}_{2} \mathrm{~F}_{\mathrm{y}}$ (i.e., density rise of a factor 1.6). Furthermore, the densities of $\mathrm{C}$ and $\mathrm{F}$ significantly decrease, while the $\mathrm{F}_{2}$ density increases a lot (see explanation below). For the ions, as seen from Fig. 4(d), the changes in the densities of $\mathrm{C}_{2} \mathrm{~F}_{\beta}^{+}$and $\mathrm{C}_{3} \mathrm{~F}_{\gamma}^{+}$are quite limited. However, the density of the lightest ions $\mathrm{CF}_{\alpha}^{+}$decreases significantly so that it becomes lower than the $\mathrm{C}_{2} \mathrm{~F}_{\beta}^{+}$density. Meanwhile, the density of the heaviest $\mathrm{C}_{4} \mathrm{~F}_{7}^{+}$ions largely increases and is now equal to the $\mathrm{C}_{3} \mathrm{~F}_{\gamma}^{+}$density. Hence, this behavior is in agreement with the trend for the neutrals, i.e., the density of the heavier ions increases more with pressure than the density of the lighter ions.

In contrast to the pressure effect, when increasing the power, the densities of all fc neutral species slightly decrease, but the effect is very limited, as observed from Fig. 4(e). Only the $\mathrm{C}$ and $\mathrm{F}$ densities increase more significantly. For the ions in Fig. 4(f), the $\mathrm{C}_{2} \mathrm{~F}_{\beta}^{+}, \mathrm{C}_{3} \mathrm{~F}_{\gamma}^{+}$, and $\mathrm{C}_{4} \mathrm{~F}_{7}^{+}$densities are almost unchanged, but the $\mathrm{CF}_{\alpha}^{+}$ion density becomes almost twice as high, i.e., from $4.1 \times 10^{10} \mathrm{~cm}^{-3}$ at $500 \mathrm{~W}$ to $7.4 \times 10^{10} \mathrm{~cm}^{-3}$ at $900 \mathrm{~W}$. Hence, a higher power promotes the formation of lighter species, because of the more prominent dissociation reactions. More detailed explanations of the effect of pressure and power on the fragmentation behavior will be given below.

In order to explain this fragmentation behavior, we first need to investigate the electron behavior, i.e., the temperature $\left(\mathrm{T}_{\mathrm{e}}\right)$ and density $\left(\mathrm{n}_{\mathrm{e}}\right)$, and the electron energy probability functions (EEPFs), which are plotted in Figures 5-7, for the three different discharge conditions shown in Fig. 4. As can be seen from Figs. 5(a)-5(c), the maximum in $\mathrm{T}_{\mathrm{e}}$ is not changed upon increasing gas pressure from 10 mTorr to 50 mTorr, but at 50 mTorr the profile is more localized under the dielectric window, due to the short electron mean free path (EMFP) at high pressure. Upon increasing power, the $\mathrm{T}_{\mathrm{e}}$ profile is almost unchanged, however, the maximum of $\mathrm{T}_{\mathrm{e}}$ at $900 \mathrm{~W}$ is a little higher than at $500 \mathrm{~W}$; see the color legends. In Figs. 5(d)-5(f), the electron density profiles in the three cases are shown. Upon increasing pressure and power, the (a) $10 \mathrm{mT}$ orr-500W

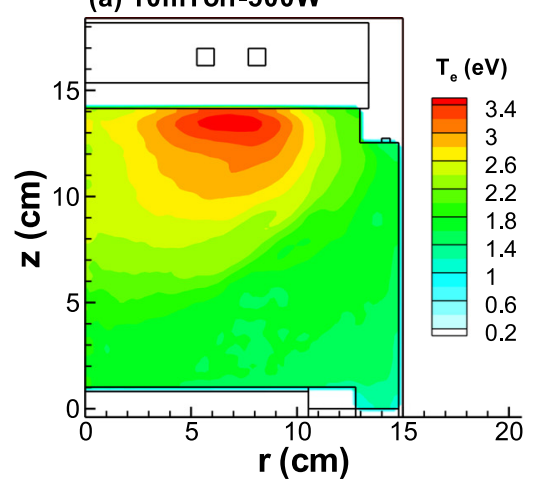

(d) $10 \mathrm{mT}$ Torr-500W

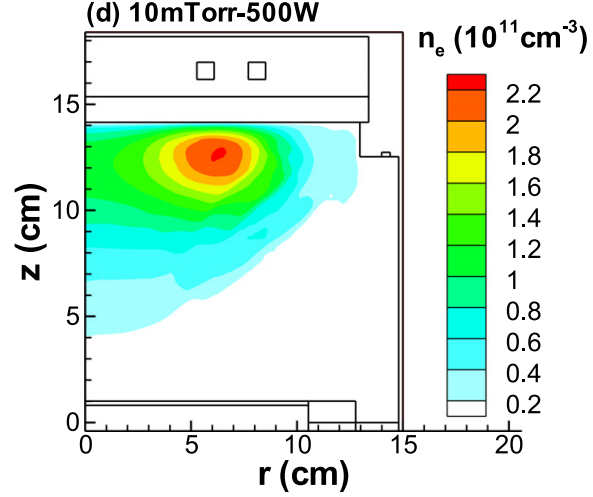

(b) $50 \mathrm{mT}$ orr-500W

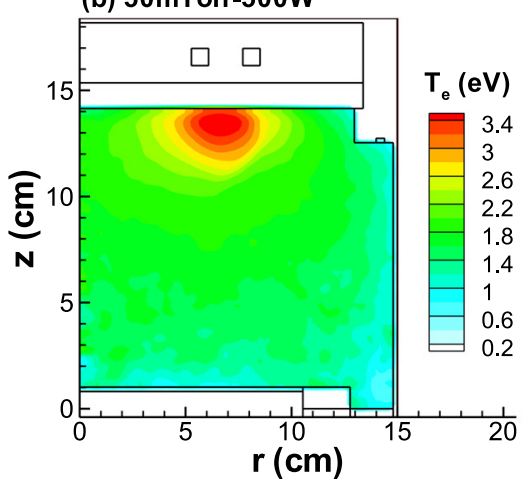

(e) $50 \mathrm{mT}$ orr-500W

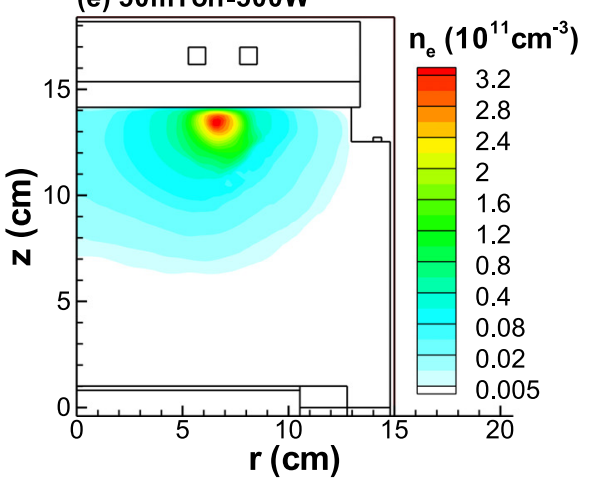

(c) $10 \mathrm{mT}$ orr-900W

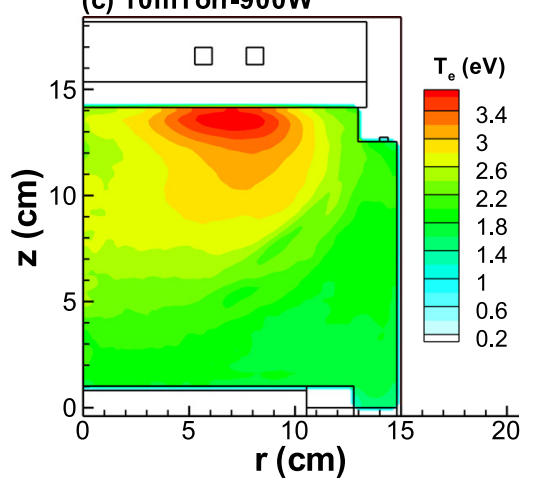

(f) $10 \mathrm{mT}$ orr-900W

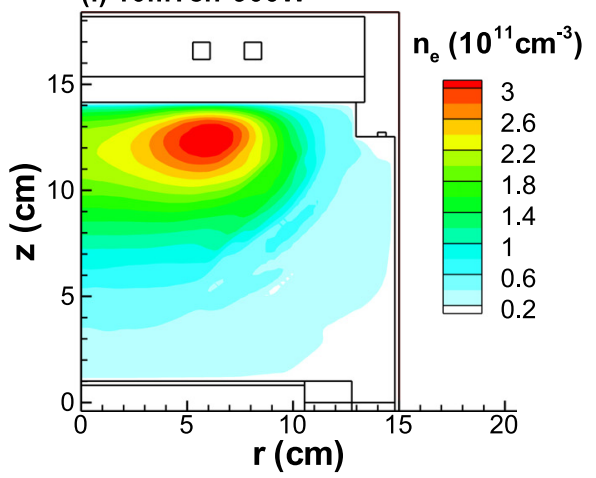

FIG. 5. Calculated electron temperature (a)-(c) and density profiles (d)-(f) at the same discharge conditions as in Fig. 4, i.e., variation of power and pressure. 
(a)

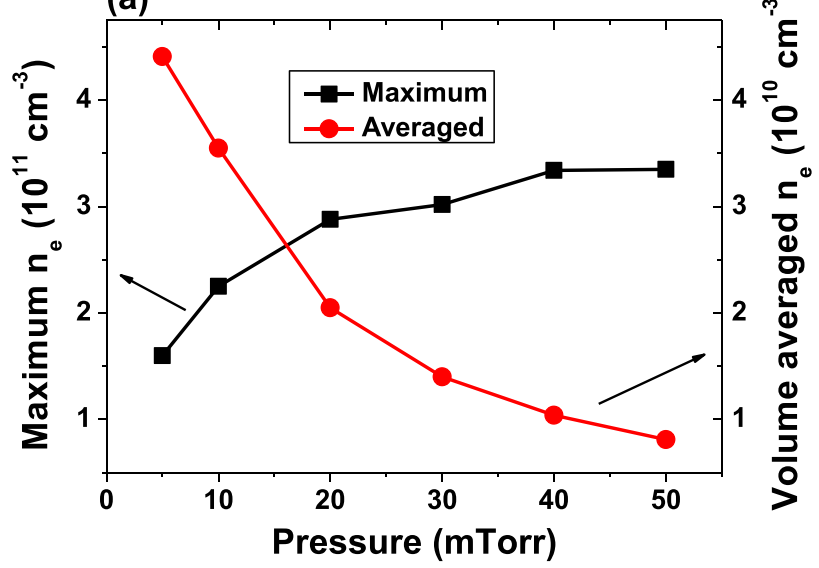

(b)

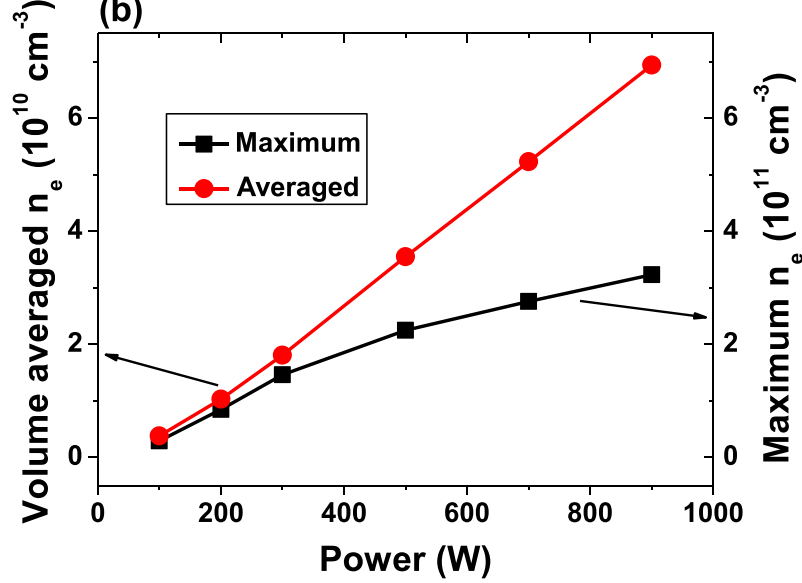

FIG. 6. Calculated maximum and volume averaged electron density $\mathrm{n}_{\mathrm{e}}$, (a) versus pressure at a power of $500 \mathrm{~W}$, and (b) versus power at a pressure of 10 mTorr. The other discharge parameters are the same as in Figs. 3 and 4.

maximum $n_{e}$ values increase, which is caused either by the higher collision rate of the electrons with the background gas (at high pressure) or by the strong heating of the electric field (at high power). However, the $\mathrm{n}_{\mathrm{e}}$ profile at $50 \mathrm{mTorr}$ is more localized under the dielectric window due to the short EMFP, as illustrated by the $T_{e}$ profile in Fig. 5(b). To further investigate the effects of localization on the electron density behavior, the maximum and volume averaged electron densities are plotted versus pressure and power in Fig. 6. As can be seen from Fig. 6(a), the maximum electron density indeed increases with pressure, but due to the spatial localization effect, the volume averaged value decreases. In Fig. 6(b), since no localization effect exists, both the maximum and volume averaged $n_{e}$ values increase with power. These trends are useful for explaining the fragmentation scheme, especially for the dissociation degree (see below).

From Fig. 7, it is clear that the EEPF at 10 mTorr and $500 \mathrm{~W}$ exhibits a two-temperature Maxwellian shape. At the higher pressure of $50 \mathrm{mTorr}$, the high-energy tail of the EEPF is severely depleted due to energy losses by inelastic collisions, whereas at the higher power of $900 \mathrm{~W}$, the highenergy tail is longer, because of the intensive heating effect by the stronger electric field.

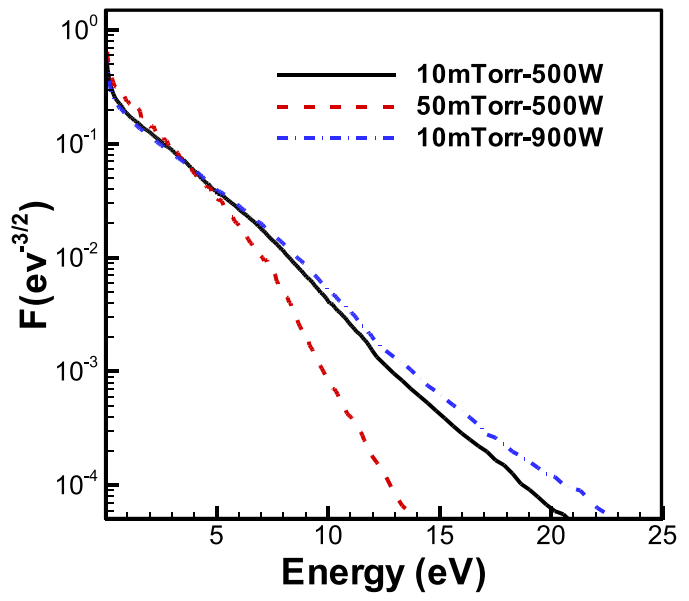

FIG. 7. EEPFs, calculated in the area under the dielectric window (i.e., $r=$ $7 \mathrm{~cm}$ and $\mathrm{z}=13 \mathrm{~cm})$, at the same discharge conditions as in Fig. 4.
The main generation sources for the fc neutrals, i.e., $\mathrm{CF}_{\mathrm{x}}, \mathrm{C}_{2} \mathrm{~F}_{\mathrm{y}}, \mathrm{C}_{3} \mathrm{~F}_{\mathrm{z}}, \mathrm{C}_{4} \mathrm{~F}_{7}$, as well as for the $\mathrm{C}$ and $\mathrm{F}$ atoms and the fc positive ions, i.e., $\mathrm{CF}_{\alpha}^{+}, \mathrm{C}_{2} \mathrm{~F}_{\beta}{ }^{+}, \mathrm{C}_{3} \mathrm{~F}_{\gamma}{ }^{+}, \mathrm{C}_{4} \mathrm{~F}_{7}{ }^{+}$, are listed in Tables IV and $\mathrm{V}$, which allow to explain the fragmentation behavior for the different discharge conditions. Note that only the primary neutral and ion generation sources are considered, since the $\mathrm{C}_{4} \mathrm{~F}_{8}$ reaction set is rather complicated. The selecting principle for the main generation channels is that (i) either the reactant concentrations are high, or (ii) the reaction cross section magnitude is large, or (iii) the reaction energy threshold is low, or (iv) the reactions are the only source for specific fc species. Besides, we focus only on the electron impact reactions, since we believe that the variation in discharge conditions mainly affects the electron

TABLE IV. Main generation sources for the fc neutrals, based on electron impact reactions. The secondary processes indicate the reactions happening between the electrons and the fragmented species. Details about the secondary reactions can be found in our previous papers. ${ }^{45,46}$

\begin{tabular}{|c|c|c|}
\hline Neutrals & Primary processes & Secondary processes \\
\hline $\mathrm{CF}_{\mathrm{x}}$ & $\begin{array}{c}\mathrm{e}+\mathrm{C}_{4} \mathrm{~F}_{8} \rightarrow \mathrm{C}_{3} \mathrm{~F}_{5}{ }^{+}+\mathrm{CF}_{3}+\mathrm{e}+\mathrm{e} \\
\mathrm{e}+\mathrm{C}_{4} \mathrm{~F}_{8} \rightarrow \mathrm{C}_{3} \mathrm{~F}_{6}+\mathrm{CF}_{2}+\mathrm{e}\end{array}$ & $\begin{array}{c}\mathrm{e}+\mathrm{C}_{2} \mathrm{~F}_{4} \rightarrow 2 \mathrm{CF}_{2}+\mathrm{e} \\
\mathrm{e}+\mathrm{CF}_{4} \rightarrow \mathrm{CF}_{3}+\mathrm{F}+\mathrm{e} \\
\mathrm{e}+\mathrm{CF}_{4} \rightarrow \mathrm{CF}_{2}+\mathrm{F}+\mathrm{F}+\mathrm{e} \\
\mathrm{e}+\mathrm{CF}_{4} \rightarrow \mathrm{CF}+\mathrm{F}+\mathrm{F}_{2}+\mathrm{e} \\
\mathrm{e}+\mathrm{CF}_{3} \rightarrow \mathrm{CF}_{2}+\mathrm{F}+\mathrm{e} \\
\mathrm{e}+\mathrm{CF}_{2} \rightarrow \mathrm{CF}+\mathrm{F}+\mathrm{e}\end{array}$ \\
\hline $\mathrm{C}_{2} \mathrm{~F}_{\mathrm{y}}$ & $\begin{array}{c}\mathrm{e}+\mathrm{C}_{4} \mathrm{~F}_{8} \rightarrow \mathrm{C}_{2} \mathrm{~F}_{4}+\mathrm{C}_{2} \mathrm{~F}_{4}+\mathrm{e} \\
\mathrm{e}+\mathrm{C}_{4} \mathrm{~F}_{8} \rightarrow \mathrm{C}_{2} \mathrm{~F}_{4}^{+}+\mathrm{C}_{2} \mathrm{~F}_{4}+\mathrm{e}+\mathrm{e}\end{array}$ & $\ldots$ \\
\hline $\mathrm{C}_{3} \mathrm{~F}_{\mathrm{z}}$ & $\begin{array}{c}\mathrm{e}+\mathrm{C}_{4} \mathrm{~F}_{8} \rightarrow \mathrm{CF}_{3}^{+}+\mathrm{C}_{3} \mathrm{~F}_{5}+\mathrm{e}+\mathrm{e} \\
\mathrm{e}+\mathrm{C}_{4} \mathrm{~F}_{8} \rightarrow \mathrm{CF}_{2}^{+}+\mathrm{C}_{3} \mathrm{~F}_{6}+\mathrm{e}+\mathrm{e} \\
\mathrm{e}+\mathrm{C}_{4} \mathrm{~F}_{8} \rightarrow \mathrm{CF}^{+}+\mathrm{C}_{3} \mathrm{~F}_{7}+\mathrm{e}+\mathrm{e} \\
\mathrm{e}+\mathrm{C}_{4} \mathrm{~F}_{8} \rightarrow \mathrm{C}_{3} \mathrm{~F}_{6}+\mathrm{CF}_{2}+\mathrm{e}\end{array}$ & $\cdots$ \\
\hline $\mathrm{C}_{4} \mathrm{~F}_{7}$ & $\begin{array}{c}\mathrm{e}+\mathrm{C}_{4} \mathrm{~F}_{8} \rightarrow \mathrm{F}^{+}+\mathrm{C}_{4} \mathrm{~F}_{7}+\mathrm{e}+\mathrm{e} \\
\mathrm{e}+\mathrm{C}_{4} \mathrm{~F}_{8} \rightarrow \mathrm{F}^{-}+\mathrm{C}_{4} \mathrm{~F}_{7}\end{array}$ & $\cdots$ \\
\hline $\mathrm{C}$ and $\mathrm{F}$ & $\ldots$ & $\begin{array}{c}\mathrm{e}+\mathrm{CF}_{4} \rightarrow \mathrm{CF}_{3}+\mathrm{F}+\mathrm{e} \\
\mathrm{e}+\mathrm{CF}_{4} \rightarrow \mathrm{CF}_{2}+\mathrm{F}+\mathrm{F}+\mathrm{e} \\
\mathrm{e}+\mathrm{CF}_{4} \rightarrow \mathrm{CF}+\mathrm{F}+\mathrm{F}_{2}+\mathrm{e} \\
\mathrm{e}+\mathrm{CF}_{3} \rightarrow \mathrm{CF}_{2}+\mathrm{F}+\mathrm{e} \\
\mathrm{e}+\mathrm{CF}_{2} \rightarrow \mathrm{CF}+\mathrm{F}+\mathrm{e} \\
\mathrm{e}+\mathrm{CF} \rightarrow \mathrm{C}+\mathrm{F}+\mathrm{e}\end{array}$ \\
\hline
\end{tabular}


TABLE V. Main generation sources for fc positive ions based on electron impact reactions.

\begin{tabular}{|c|c|c|}
\hline $\begin{array}{l}\text { Positive } \\
\text { ions }\end{array}$ & Primary processes & Secondary processes \\
\hline $\mathrm{CF}_{\alpha}^{+}$ & $\begin{array}{c}\mathrm{e}+\mathrm{C}_{4} \mathrm{~F}_{8} \rightarrow \mathrm{CF}_{3}^{+}+\mathrm{C}_{3} \mathrm{~F}_{5}+\mathrm{e}+\mathrm{e} \\
\mathrm{e}+\mathrm{C}_{4} \mathrm{~F}_{8} \rightarrow \mathrm{CF}_{2}^{+}+\mathrm{C}_{3} \mathrm{~F}_{6}+\mathrm{e}+\mathrm{e} \\
\mathrm{e}+\mathrm{C}_{4} \mathrm{~F}_{8} \rightarrow \mathrm{CF}^{+}+\mathrm{C}_{3} \mathrm{~F}_{7}+\mathrm{e}+\mathrm{e}\end{array}$ & $\begin{array}{c}\mathrm{e}+\mathrm{CF}_{4} \rightarrow \mathrm{CF}_{3}^{+}+\mathrm{F}+2 \mathrm{e} \\
\mathrm{e}+\mathrm{CF}_{4} \rightarrow \mathrm{CF}_{2}^{+}+\mathrm{F}+\mathrm{F}+2 \mathrm{e} \\
\mathrm{e}+\mathrm{CF}_{4} \rightarrow \mathrm{CF}^{+}+\mathrm{F}+\mathrm{F}_{2}+2 \mathrm{e} \\
\mathrm{e}+\mathrm{CF}_{3} \rightarrow \mathrm{CF}_{3}^{+}+2 \mathrm{e} \\
\mathrm{e}+\mathrm{CF}_{3} \rightarrow \mathrm{CF}_{2}^{+}+\mathrm{F}+2 \mathrm{e} \\
\mathrm{e}+\mathrm{CF}_{3} \rightarrow \mathrm{CF}^{+}+\mathrm{F}+\mathrm{F}+2 \mathrm{e} \\
\mathrm{e}+\mathrm{CF}_{2} \rightarrow \mathrm{CF}_{2}^{+}+2 \mathrm{e} \\
\mathrm{e}+\mathrm{CF}_{2} \rightarrow \mathrm{CF}^{+}+\mathrm{F}+2 \mathrm{e} \\
\mathrm{e}+\mathrm{CF} \rightarrow \mathrm{CF}^{+}+2 \mathrm{e}\end{array}$ \\
\hline $\mathrm{C}_{2} \mathrm{~F}_{\beta}^{+}$ & $\mathrm{e}+\mathrm{C}_{4} \mathrm{~F}_{8} \rightarrow \mathrm{C}_{2} \mathrm{~F}_{4}^{+}+\mathrm{C}_{2} \mathrm{~F}_{4}+\mathrm{e}+\mathrm{e}$ & $\mathrm{e}+\mathrm{C}_{2} \mathrm{~F}_{4} \rightarrow \mathrm{C}_{2} \mathrm{~F}_{4}^{+}+\mathrm{e}+\mathrm{e}$ \\
\hline $\mathrm{C}_{3} \mathrm{~F}_{\gamma}^{+}$ & $\mathrm{e}+\mathrm{C}_{4} \mathrm{~F}_{8} \rightarrow \mathrm{C}_{3} \mathrm{~F}_{5}^{+}+\mathrm{CF}_{3}+\mathrm{e}+\mathrm{e}$ & \\
\hline $\mathrm{C}_{4} \mathrm{~F}_{7}^{+}$ & $\ldots$ & $\mathrm{e}+\mathrm{C}_{4} \mathrm{~F}_{7} \rightarrow \mathrm{C}_{4} \mathrm{~F}_{7}{ }^{+}+\mathrm{e}+\mathrm{e}$ \\
\hline
\end{tabular}

properties, such as the electron density, temperature, and energy distribution function, as is clear from Figures 5-7 above. It should be noted that for reactions 1-12 in Table II, the rate coefficients are directly used, which are obtained by integration, based on a Maxwellian-type assumed EEDF. For these 12 reactions, only reaction 11 is chosen as an important reaction and included in Table $\mathrm{V}$, by using the above selecting principle evaluating system.

The main generation channels for fc neutrals and positive ions, based on electron reactions, are classified into two types, i.e., so-called primary processes and secondary processes. The primary processes represent the reactions occurring between the electrons and the background molecules $\mathrm{C}_{4} \mathrm{~F}_{8}$, while the secondary processes represent the reactions occurring between the electrons and the various fragmented neutral species.

The behavior of the $T_{e}$ and $n_{e}$ profiles and magnitudes, and the EEPFs, together with the information about the main generation sources for the fc species, as well as the dissociation degree and the specific density ratios presented in Sec. III A, can now be used to explain the fragmentation trends upon increase of pressure and power, as illustrated in Figs. 3 and 4 above.

First, we focus on the pressure effect on the neutrals. As shown in Fig. 3(a), when the pressure increases from 10 mTorr to 50 mTorr, the dissociation degree drops from about 0.77 to 0.17 . Hence, at $10 \mathrm{mTorr}$, the fragmented fc neutrals are dominant, with a density about 3.5 times the $\mathrm{C}_{4} \mathrm{~F}_{8}$ density, whereas at 50 mTorr, the density of $\mathrm{C}_{4} \mathrm{~F}_{8}$ is about five times larger than the sum of the fragmented $\mathrm{fc}$ neutral densities. This is logical, because at high pressure, the $\mathrm{C}_{4} \mathrm{~F}_{8}$ density is high and there will be more $\mathrm{C}_{4} \mathrm{~F}_{8}$ molecules in the chamber, which cannot all be dissociated. Moreover, as mentioned before, due to the localization effect, although the maximum electron density increases with pressure, the volume averaged $n_{e}$ value is reduced; cf. Fig. 6. The lower mean electron density at high pressure can also explain the lower dissociation degree. Indeed, the dissociation degree itself is also spatially integrated. On the other hand, at low pressure, there is less $\mathrm{C}_{4} \mathrm{~F}_{8}$ present in the reactor, and a larger fraction of the $\mathrm{C}_{4} \mathrm{~F}_{8}$ molecules can be dissociated, also because a larger fraction of high energy electrons are present (cf. Figure 7). As a result, the production of fc neutrals and ions evolves from secondary-process dominated to primary-process dominated, upon increasing pressure. Therefore, the densities of the fc neutrals of $\mathrm{C}_{2} \mathrm{~F}_{\mathrm{y}}$, $\mathrm{C}_{3} \mathrm{~F}_{\mathrm{z}}$, and $\mathrm{C}_{4} \mathrm{~F}_{7}$, which are purely produced by primary processes in our model (see Table IV), significantly increase upon higher pressure. On the other hand, the density of the F neutrals, which are purely produced by secondary processes, significantly decreases. Finally, the density of the $\mathrm{CF}_{\mathrm{x}}$ neutrals, which are produced by both primary and secondary processes, increases only slightly, because of the two competing effects of the primary-processes and secondaryprocesses.

It is more complicated to analyze the effect of gas pressure on the ions. As illustrated in Fig. 3(c), the density ratio of all fc neutrals vs. all fc positive ions increases upon increasing pressure, from about 1400 to 3300 . Besides a high concentration of the parent background $\mathrm{C}_{4} \mathrm{~F}_{8}$ molecules, also many fc neutrals are present, due to the strong parent dissociation processes. Hence, besides the $\mathrm{C}_{4} \mathrm{~F}_{8}$ molecules, the fc neutrals also play an important role for the various ionization channels. As a result, the primary and secondary ionization processes may be both important and need to be considered. From Table V, we can see that the $\mathrm{C}_{4} \mathrm{~F}_{7}^{+}$ions are exclusively formed by a secondary process, whereas the $\mathrm{C}_{3} \mathrm{~F}_{\gamma}^{+}$ions are only created by a primary process. As the $\mathrm{C}_{4} \mathrm{~F}_{7}^{+}$ion density increases with pressure, and the $\mathrm{C}_{3} \mathrm{~F}_{\gamma}^{+}$ion density is almost unchanged, we can conclude that for the ion generation at high pressure, the secondary process is probably dominant over the primary process.

The drop of the $\mathrm{CF}_{\alpha}^{+}$density can be explained by the combination of two factors. The first effect is the relatively low $\mathrm{CF}_{\mathrm{x}}$ density, compared to the other $\mathrm{C}_{\mathrm{x}} \mathrm{F}_{\mathrm{y}}$ neutrals; see Fig. 4(c). The other effect is related to the EEPF. As illustrated in Fig. 7, the high energy tail of the EEPF is depleted at high pressure. It implies that there may not be enough high-energy electrons to induce some inelastic collisions with very high threshold energy. Indeed, both the primary and secondary generation processes of $\mathrm{CF}_{\alpha}^{+}$ions have a higher threshold energy than for the other ions (i.e., $\mathrm{C}_{2} \mathrm{~F}_{\beta}^{+}$ and $\mathrm{C}_{3} \mathrm{~F}_{\gamma}^{+}$), explaining the drop in $\mathrm{CF}_{\alpha}^{+}$ion density.

To understand the power effect on the neutral components, we have to look first at the dissociation degree against power, plotted in Fig. 3(d). At the power of $900 \mathrm{~W}$, the dissociation degree is 0.67 , and thus the ratio of the parent $\mathrm{C}_{4} \mathrm{~F}_{8}$ density to the fragmented neutral density is calculated to be about $1: 3$. Thus, the primary and secondary processes both play a role, but the secondary processes will be more important. Indeed, the densities of the $\mathrm{C}$ and $\mathrm{F}$ atoms, which are exclusively formed by the secondary processes, clearly increase. Besides, we can deduce from Fig. 4(e) that all $\mathrm{C}_{\mathrm{x}} \mathrm{F}_{\mathrm{y}}$ densities decrease at increasing power, whereas the total ion density significantly increases (cf. Table III). The drop in total $\mathrm{C}_{\mathrm{x}} \mathrm{F}_{\mathrm{y}}$ density and the prominent increase in ion density suggest that a larger fraction of the plasma-deposited energy is consumed by the ionization scheme at higher power values. 
The effect of power on the ion components can be explained from the EEPF, which has a longer high energy tail at higher power, and therefore it contains a larger fraction of fast electrons. Hence, the deposited energy is mainly used for the ionization reactions, which usually have a high energy threshold. Besides, as mentioned above, the feedstock $\mathrm{C}_{4} \mathrm{~F}_{8}$ molecules are severely depleted in the heating region (under the dielectric window) where most ionization and dissociation occur. Thus, although the spatially averaged $\mathrm{C}_{4} \mathrm{~F}_{8}$ density is in the same order as the total $\mathrm{C}_{\mathrm{x}} \mathrm{F}_{\mathrm{y}}$ radical density, the density of $\mathrm{C}_{4} \mathrm{~F}_{8}$ in the heating region is about two orders low than the total $\mathrm{C}_{\mathrm{x}} \mathrm{F}_{\mathrm{y}}$ radical density. Therefore, we can conclude that the secondary ionizations arising from the fragmented $\mathrm{C}_{\mathrm{x}} \mathrm{F}_{\mathrm{y}}$ radicals should be more pronounced than primary ionization from $\mathrm{C}_{4} \mathrm{~F}_{8}$. Moreover, since the $\mathrm{CF}_{\mathrm{x}}$ neutrals have the highest density, ionization from these species should be more prominent, and hence the density of the $\mathrm{CF}_{\alpha}^{+}$ increases most.

Finally, the evolution of the $\mathrm{F}$ vs. $\mathrm{C}_{\mathrm{x}} \mathrm{F}_{\mathrm{y}}$ density ratio with changing discharge conditions, as plotted in Figs. 3(b) and 3(e), can also be explained by the above mechanism. With increasing pressure, the $\mathrm{C}_{\mathrm{x}} \mathrm{F}_{\mathrm{y}}$ densities increase a lot and the $\mathrm{F}$ density decreases, due to the dominant primary dissociation processes, producing mainly $\mathrm{C}_{\mathrm{x}} \mathrm{F}_{\mathrm{y}}$ species and no $\mathrm{F}$ atoms. Therefore, the $\mathrm{F}$ vs. $\mathrm{C}_{\mathrm{x}} \mathrm{F}_{\mathrm{y}}$ density ratio decreases with pressure. With increasing power, the secondary dissociation processes dominate, and thus the $\mathrm{F}$ density increases. At the same time, the total $\mathrm{C}_{\mathrm{x}} \mathrm{F}_{\mathrm{y}}$ density decreases, because (i) the primary dissociation process becomes less important, and (ii) the secondary ionization processes become more important. This explains the increase in the $F$ vs. $\mathrm{C}_{\mathrm{x}} \mathrm{F}_{\mathrm{y}}$ density ratio upon increasing power.

\section{Fractions of the various fc neutrals and ions}

As we know, the fc film formed on the substrate plays an important role in the etching process; however, until now the precursor species for the film growth are still under dispute. Some authors report that the light fc neutrals, i.e.,
$\mathrm{CF}_{\mathrm{x}}$, are responsible, ${ }^{34,56}$ while others claim that the heavy species, i.e., $\mathrm{C}_{\mathrm{x}(\mathrm{x}>2)} \mathrm{F}_{\mathrm{y}}$, are dominant. ${ }^{33,35}$ Therefore, in this section, we present the fractions of various fc neutrals, expressed as their densities divided by the total fc neutral density (i.e., the sum of $\mathrm{CF}_{\mathrm{x}}, \mathrm{C}_{2} \mathrm{~F}_{\mathrm{y}}, \mathrm{C}_{3} \mathrm{~F}_{\mathrm{z}}$, and $\mathrm{C}_{4} \mathrm{~F}_{7}$ ), as well as the fractions of various fc ions with respect to the total $\mathrm{fc}$ ion density (i.e., the sum of $\mathrm{CF}_{\alpha}{ }^{+}, \mathrm{C}_{2} \mathrm{~F}_{\beta}{ }^{+}, \mathrm{C}_{3} \mathrm{~F}_{\gamma}{ }^{+}, \mathrm{C}_{4} \mathrm{~F}_{7}{ }^{+}$).

In Fig. 8, the fractions of fc neutrals and ions are plotted as a function of pressure. With increasing pressure, the $\mathrm{CF}_{\mathrm{x}}$ fraction decreases and the $\mathrm{C}_{2} \mathrm{~F}_{\mathrm{y}}$ fraction increases, as is clear from Fig. 8(a). Nevertheless, the $\mathrm{CF}_{\mathrm{x}}$ fraction is always larger than the $\mathrm{C}_{2} \mathrm{~F}_{\mathrm{y}}$ fraction. The heavier fc neutrals clearly have lower densities in the entire pressure range, and the $\mathrm{C}_{4} \mathrm{~F}_{7}$ fraction is larger than the $\mathrm{C}_{3} \mathrm{~F}_{\mathrm{z}}$ fraction. This can be explained by referring to the main generation sources of the various fc neutrals in Table IV. Indeed, $\mathrm{CF}_{\mathrm{x}}$ has two generation sources, i.e., based on both primary and secondary processes, but the other $\mathrm{C}_{\mathrm{x}} \mathrm{F}_{\mathrm{y}}$ species, i.e., $\mathrm{C}_{2} \mathrm{~F}_{\mathrm{y}}, \mathrm{C}_{3} \mathrm{~F}_{\mathrm{z}}$, and $\mathrm{C}_{4} \mathrm{~F}_{7}$, are only formed by primary processes. That is why the fraction of $\mathrm{CF}_{\mathrm{x}}$ is always the highest. Besides, the $\mathrm{C}_{2} \mathrm{~F}_{\mathrm{y}}$ species are also very important, and the reason is that one of their primary processes, i.e., e $+\mathrm{C}_{4} \mathrm{~F}_{8} \rightarrow \mathrm{C}_{2} \mathrm{~F}_{4}+\mathrm{C}_{2} \mathrm{~F}_{4}+\mathrm{e}$, has a very high cross section and a rather low threshold energy, i.e., $8 \mathrm{eV}$. With increasing pressure, as mentioned above, the primary processes gradually dominate over the secondary processes. Hence, the $\mathrm{C}_{\mathrm{x}} \mathrm{F}_{\mathrm{y}}$ fractions, produced exclusively by primary processes, increase, at the expense of the $\mathrm{CF}_{\mathrm{x}}$ fraction.

Fig. 8(b) illustrates the fractions of the various fc ions as a function of gas pressure. Both the $\mathrm{CF}_{\alpha}{ }^{+}$and $\mathrm{C}_{2} \mathrm{~F}_{\beta}{ }^{+}$ions dominate the discharge. The $\mathrm{CF}_{\alpha}{ }^{+}$fraction is the largest at low pressure, but above 27 mTorr the $\mathrm{C}_{2} \mathrm{~F}_{\beta}{ }^{+}$fraction becomes dominant. The $\mathrm{C}_{3} \mathrm{~F}_{\gamma}{ }^{+}$and $\mathrm{C}_{4} \mathrm{~F}_{7}{ }^{+}$fractions are again the smallest. For the explanation we refer to Table V, where the main generation sources for the various fc ions are presented. The relatively light ions, i.e., $\mathrm{CF}_{\alpha}{ }^{+}$and $\mathrm{C}_{2} \mathrm{~F}_{\beta}{ }^{+}$, have both primary and secondary generation sources, but for the heavy ions either pure primary processes are involved, e.g., for $\mathrm{C}_{3} \mathrm{~F}_{\gamma}{ }^{+}$, or pure secondary processes, like for $\mathrm{C}_{4} \mathrm{~F}_{7}{ }^{+}$. That
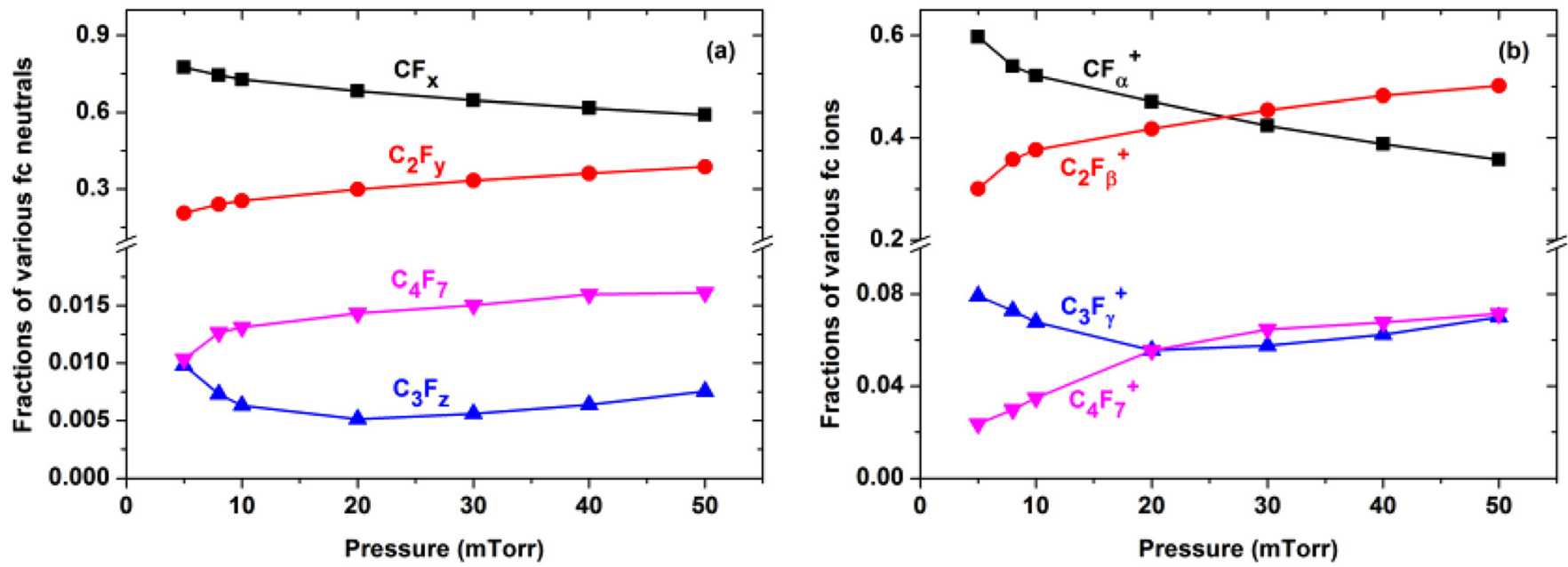

FIG. 8. Calculated fractions of various fc neutral components, i.e., $\mathrm{CF}_{\mathrm{x}}, \mathrm{C}_{2} \mathrm{~F}_{\mathrm{y}}, \mathrm{C}_{3} \mathrm{~F}_{\mathrm{z}}$, and $\mathrm{C}_{4} \mathrm{~F}_{7}$, with respect to the total $\mathrm{C}_{\mathrm{x}} \mathrm{F}_{\mathrm{y}}$ neutral density (a) and fractions of various fc positive ions, i.e., $\mathrm{CF}_{\alpha}{ }^{+}, \mathrm{C}_{2} \mathrm{~F}_{\beta}{ }^{+}, \mathrm{C}_{3} \mathrm{~F}_{\gamma}{ }^{+}, \mathrm{C}_{4} \mathrm{~F}_{7}{ }^{+}$, with respect to the total $\mathrm{C}_{\mathrm{x}} \mathrm{F}_{\mathrm{y}}{ }^{+}$ion density (b), as a function of pressure. The coil power is fixed at $500 \mathrm{~W}$. 
is why the $\mathrm{CF}_{\alpha}{ }^{+}$and $\mathrm{C}_{2} \mathrm{~F}_{\beta}{ }^{+}$are clearly more important than the $\mathrm{C}_{3} \mathrm{~F}_{\gamma}{ }^{+}$and $\mathrm{C}_{4} \mathrm{~F}_{7}{ }^{+}$ions. To validate our findings, we again refer to the experimental work of $\mathrm{Li}$ et $a ._{.}{ }^{26}$ at similar discharge conditions, i.e., 6 mTorr and 600 W. In Fig. 7 of Ref. 26 , the relative fluxes of the main fc positive ions were presented. Taking together the ions with the same number of $\mathrm{C}$ atoms, the ratios of the ion fluxes of $\mathrm{CF}_{\alpha}{ }^{+}, \mathrm{C}_{2} \mathrm{~F}_{\beta}{ }^{+}, \mathrm{C}_{3} \mathrm{~F}_{\gamma}{ }^{+}$, $\mathrm{C}_{4} \mathrm{~F}_{7}{ }^{+}$can be calculated as 0.762: 0.144: 0.091: 0.003. For comparison, the calculated ratios of fc ions in our model at similar conditions, i.e., $5 \mathrm{mTorr}$ and $500 \mathrm{~W}$, are about 0.6: 0.3: $0.08: 0.02$, which is in reasonable agreement with the experiment.

Furthermore, the drop in the $\mathrm{CF}_{\alpha}{ }^{+}$fraction and the growth of the $\mathrm{C}_{2} \mathrm{~F}_{\beta}{ }^{+}$fraction with pressure can be explained by the depletion of the high-energy tail of the EEPF and by the higher threshold energy for the $\mathrm{CF}_{\alpha}{ }^{+}$generation reactions, which indeed yields a drop in the $\mathrm{CF}_{\alpha}^{+}$fraction, and as a result, the $\mathrm{C}_{2} \mathrm{~F}_{\beta}{ }^{+}$fraction increases. The drop of $\mathrm{C}_{3} \mathrm{~F}_{\gamma}{ }^{+}$ and the growth of $\mathrm{C}_{4} \mathrm{~F}_{7}{ }^{+}$are caused by the fact that secondary processes gradually dominate over primary processes, at increasing pressure.

The fractions of various fc neutrals and ions as a function of applied power are plotted in Fig. 9. Again, the $\mathrm{CF}_{\mathrm{x}}$ and $\mathrm{C}_{2} \mathrm{~F}_{\mathrm{y}}$ radicals have the highest fraction in the considered power range, and the fractions of the heavier fc radicals are only a few percent. At increasing power, the $\mathrm{CF}_{\mathrm{x}}$ fraction increases and the $\mathrm{C}_{2} \mathrm{~F}_{\mathrm{y}}$ fraction decreases, and only at low power the $\mathrm{C}_{2} \mathrm{~F}_{\mathrm{y}}$ fraction is higher than the $\mathrm{CF}_{\mathrm{x}}$ fraction. By correlating with Figs. 4(a) and 4(e), we can see that although all $\mathrm{C}_{\mathrm{x}} \mathrm{F}_{\mathrm{y}}$ densities decrease with increasing power, the fraction of $\mathrm{CF}_{\mathrm{x}}$ increases and the $\mathrm{C}_{2} \mathrm{~F}_{\mathrm{y}}, \mathrm{C}_{3} \mathrm{~F}_{\mathrm{z}}$, and $\mathrm{C}_{4} \mathrm{~F}_{7}$ fractions decrease. This means that at high power, the secondary processes for the generation of fc neutrals are predominant, cf. Table IV.

For the ion fractions, the $\mathrm{CF}_{\alpha}{ }^{+}$and $\mathrm{C}_{2} \mathrm{~F}_{\beta}{ }^{+}$ions are the highest at high power (i.e., $\geq 200 \mathrm{~W}$ ). Moreover, the $\mathrm{CF}_{\alpha}{ }^{+}$ fraction increases and the $\mathrm{C}_{2} \mathrm{~F}_{\beta}{ }^{+}$fraction decreases upon rising power. This is because the secondary processes for $\mathrm{fc}$ ions and neutrals become more important, and at the same time the $\mathrm{C}_{2} \mathrm{~F}_{\mathrm{y}}$ fraction decreases and the $\mathrm{CF}_{\mathrm{x}}$ fraction increases at increasing power. Moreover, the increasing high-energy tail of the EEPF is also more beneficial for the $\mathrm{CF}_{\alpha}{ }^{+}$generation reactions since they have higher threshold energies than $\mathrm{C}_{2} \mathrm{~F}_{\beta}{ }^{+}$. Furthermore, it is striking from this figure that at low power (i.e., $\leq 150 \mathrm{~W}$ ), the $\mathrm{C}_{3} \mathrm{~F}_{\gamma}{ }^{+}$ions are more important than the $\mathrm{CF}_{\alpha}{ }^{+}$ions, which is explained by the exclusive primary generation source of $\mathrm{C}_{3} \mathrm{~F}_{5}{ }^{+}$(i.e., main $\mathrm{C}_{3} \mathrm{~F}_{\gamma}{ }^{+}$component), which has a rather low threshold, i.e., $11.5 \mathrm{eV}$; see Table II. This also explains why in a capacitively coupled plasma, when the power is rather low and the electron density is around $2 \times 10^{9} \mathrm{~cm}^{-3}$, the $\mathrm{C}_{3} \mathrm{~F}_{5}{ }^{+}$ions can even have the highest density, as revealed by experiments. ${ }^{21}$

Finally, we also compared the power dependence of our simulated neutral and ion species density fractions with the results of a $\mathrm{C}_{4} \mathrm{~F}_{8}$ global model by Kokkoris et al. ${ }^{27}$ Although in Ref. 27 all the considered neutral and charged species densities were plotted separately, it is easy to estimate that the sum of all light $\mathrm{fc}$ neutral (i.e., $\mathrm{CF}_{\mathrm{x}}$ ) densities increases with power and then saturates, which is very similar to our result in Fig. 9(a). The densities of all heavy fc neutrals in the global model, ${ }^{27}$ like $\mathrm{C}_{2} \mathrm{~F}_{3}, \mathrm{C}_{2} \mathrm{~F}_{4}$, and $\mathrm{C}_{4} \mathrm{~F}_{7}$, generally decrease with power, which is also similar to our results in Fig. 9(a). The light ion densities (i.e., $\mathrm{CF}_{\alpha}{ }^{+}$) in Ref. 27 all monotonically increase with power, also similar to our results in Fig. 9(b). Except for an increase at very low power (i.e., below our considered power range), the considered heavy ion $\mathrm{C}_{2} \mathrm{~F}_{4}{ }^{+}$density basically decreases with power, again similar to our results in Fig. 9(b). Finally, the F and $F_{2}$ densities of the global model monotonically increase with power, which is also similar to our results, illustrated in Figs. 4(a) and 4(e) above.

\section{Validation and limitations of the model}

In this section, our simulations with the hybrid model and the established $\mathrm{C}_{4} \mathrm{~F}_{8}$ reaction set are verified, by comparing the results with the experimental work of Refs. 25 and 55 for the same reactor configuration, discharge conditions, and
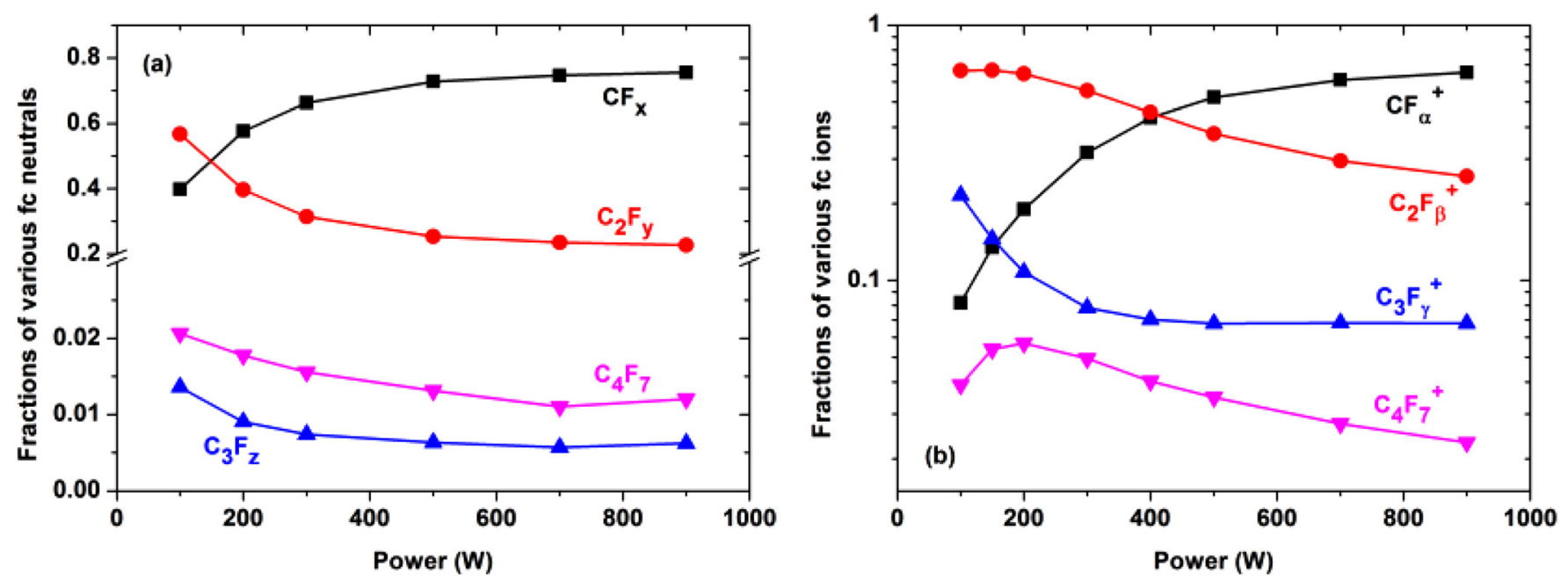

FIG. 9. Calculated fractions of various fc neutral components, i.e., $\mathrm{CF}_{\mathrm{x}}, \mathrm{C}_{2} \mathrm{~F}_{\mathrm{y}}, \mathrm{C}_{3} \mathrm{~F}_{\mathrm{z}}$, and $\mathrm{C}_{4} \mathrm{~F}_{7}$, with respect to the total $\mathrm{C}_{\mathrm{x}} \mathrm{F}_{\mathrm{y}}$ neutral density (a) and fractions of various fc positive ions, i.e., $\mathrm{CF}_{\alpha}{ }^{+}, \mathrm{C}_{2} \mathrm{~F}_{\beta}{ }^{+}, \mathrm{C}_{3} \mathrm{~F}_{\gamma}{ }^{+}, \mathrm{C}_{4} \mathrm{~F}_{7}{ }^{+}$, with respect to the total $\mathrm{C}_{\mathrm{x}} \mathrm{F}_{\mathrm{y}}{ }^{+}$ion density (b), as a function of power. The gas pressure is fixed at 10 mTorr. 


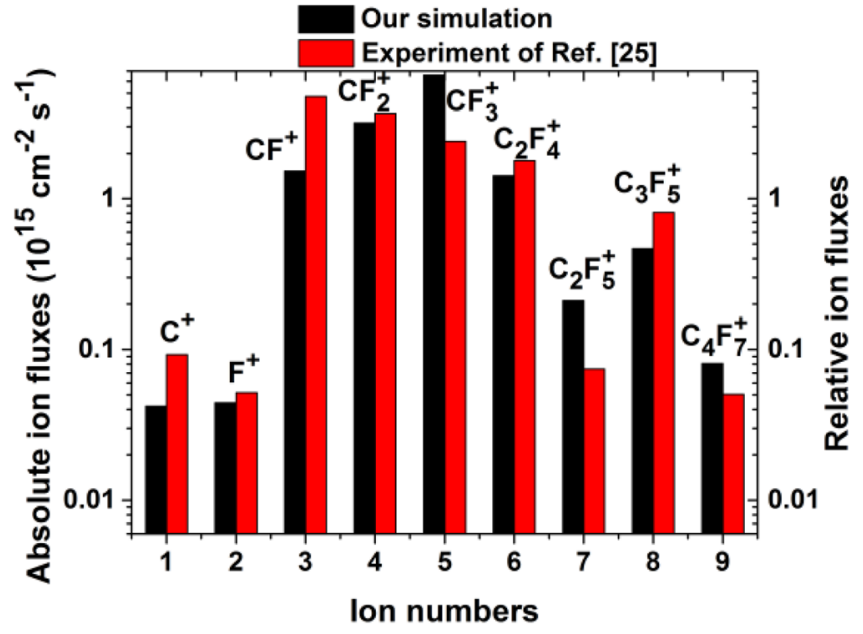

FIG. 10. Comparison between the experimentally measured relative ion fluxes in a pure $\mathrm{C}_{4} \mathrm{~F}_{8}$ ICP source from Ref. 25 (red bars) and absolute ion fluxes calculated by our model under the same discharge conditions and with the same reactor configuration as in Ref. 25 (black bars). Note that only the predominant ion species are selected for comparison. The ICP power is set at $600 \mathrm{~W}$, and the pressure is fixed at 10 mTorr. The gas flow rate is 40 sccm. The ICP reactor configuration can be found in Ref. 25. The ion fluxes are probed at the wafer edge of the chamber in both the experiment and the model.

gas components. First, the experiment of Li et al. ${ }^{25}$ was considered and reproduced here. In Ref. 25, the relative ion flux towards the wafer was measured, and these data are used here for validating our simulation. The relative ion fluxes from $\mathrm{Li}$ et al. ${ }^{25}$ together with the absolute ion fluxes towards the wafer as calculated by our hybrid model, are plotted in Fig. 10.

As seen from Fig. 10, the ion fluxes calculated in the model correlate reasonably well with the experimental values, except for the $\mathrm{CF}_{\mathrm{x}}{ }^{+}$species. Specifically, in the experiment the order of these three ion fluxes is $\mathrm{CF}^{+}$ $>\mathrm{CF}_{2}{ }^{+}>\mathrm{CF}_{3}{ }^{+}$, while in the simulation it is the opposite, i.e., $\mathrm{CF}_{3}{ }^{+}>\mathrm{CF}_{2}{ }^{+}>\mathrm{CF}^{+}$. However, as shown in the figure,

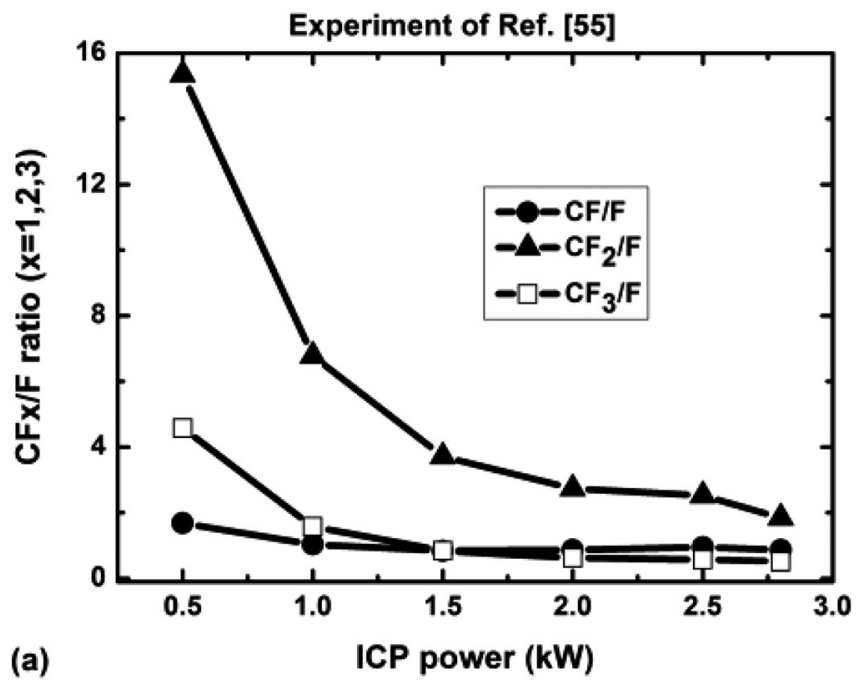

the sum of these three ion fluxes will be more or less the same in both the simulations and the experiment. As the main goal of our work is an overall study of the bulk plasma fragmentation, i.e., all the ions with single $\mathrm{C}$ atom were lumped together as $\mathrm{CF}_{\alpha}{ }^{+}$in Secs. III A-III C, we believe that the difference between the fluxes of the individual ion species should not influence our final conclusions. The relatively lower $\mathrm{CF}^{+}$and $\mathrm{CF}_{2}{ }^{+}$ion fluxes predicted by the model, especially for $\mathrm{CF}^{+}$, are probably because the surface polymer kinetics that can produce light fc radicals (like CF and $\mathrm{CF}_{2}$ ) under the bombardment of low-energy ions is not considered yet in our model. These light fc radicals are believed to significantly contribute to the generation of the light $\mathrm{fc}$ ions, as it is revealed that the ICP fc plasma sources usually have a very high dissociation degree and the dissociative products can serve as the main reactants for ionization. ${ }^{57} \mathrm{~A}$ more detailed analysis is given in Figure 11.

In Fig. 11, the $\mathrm{CF}_{\mathrm{x}}$ over $\mathrm{F}$ density ratios in a $\mathrm{C}_{4} \mathrm{~F}_{8} / \mathrm{Ar}$ mixed ICP source, measured and calculated under the same discharge conditions and with the same reactor configuration, are presented as a function of ICP power. The experimental data are taken from Ref. 55, and reproduced here. They are used here for verification of our simulations. The experimental and simulated density ratios show basically the same decreasing trends as a function of power, and the order of importance of the different radicals $\left(\mathrm{CF}_{2}>\mathrm{CF}_{3}>\mathrm{CF}\right)$ is also the same in the experimental and calculated results. The difference is that the experimental ratios are around 6 times larger than our calculated ratios. We believe that this is caused by the fact that a surface polymer formation and depletion mechanism is not included yet in our simulations. The polymer layer formed at the chamber walls and the dielectric window, under the bombardment of incident lowenergy ions, can be an important source for the creation of light $\mathrm{fc}$ radicals, such as $\mathrm{CF}, \mathrm{CF}_{2}$, and $\mathrm{CF}_{3}$, upon bombardment of low-energy ions. ${ }^{27}$ However, the lack of this surface kinetics model does not significantly influence the general

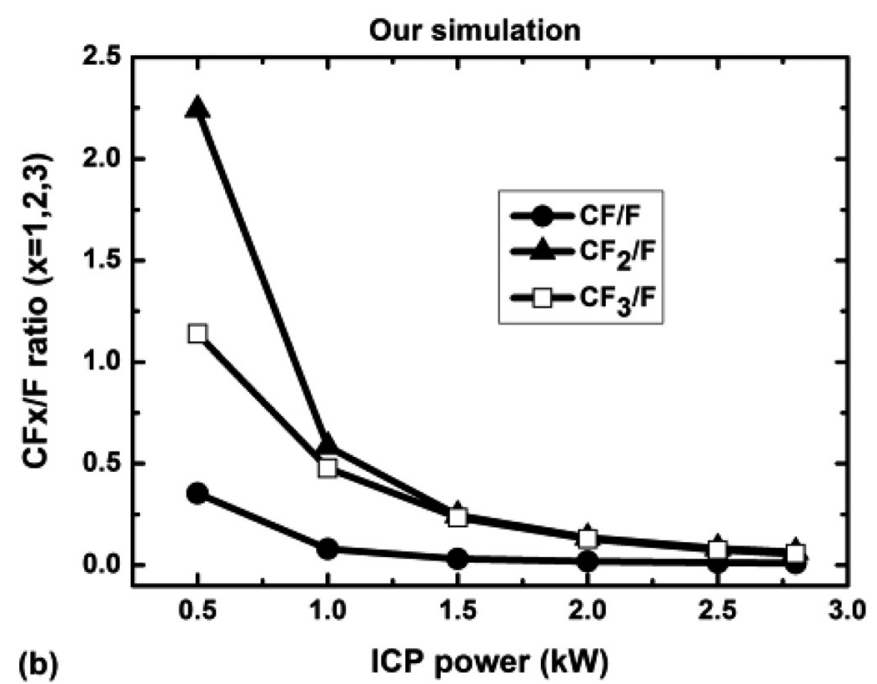

FIG. 11. (a) Experimentally measured $\mathrm{CF}_{\mathrm{x}}$ over $\mathrm{F}$ density ratios of a $\mathrm{C}_{4} \mathrm{~F}_{8} / \mathrm{Ar}$ mixed ICP source from Ref. 55, and (b) calculated $\mathrm{CF}_{\mathrm{x}}$ over $\mathrm{F}$ density ratios, obtained with our model under the same discharge conditions and with the same reactor configuration. These density ratios are varied against the applied ICP power. The pressure is fixed at $3 \mathrm{~Pa}$, and the gas content ratio of $\mathrm{C}_{4} \mathrm{~F}_{8} \mathrm{vs}$. Ar is 5:395 with a total gas flow rate of 400 sccm. The reactor configuration can be found in Ref. 55. 
trends of the density ratios against power. In addition, as revealed by Ref. 57, the addition of a buffer gas, such as Ar, hardly changes the main ion composition in the ICP fc plasma sources, such as $\mathrm{C}_{2} \mathrm{~F}_{6}$ and $\mathrm{C}_{4} \mathrm{~F}_{8}$. Thus, we believe that the above analysis obtained in the $\mathrm{C}_{4} \mathrm{~F}_{8} / \mathrm{Ar}$ mixed plasma can also apply to the pure $\mathrm{C}_{4} \mathrm{~F}_{8}$ plasma.

Finally, it needs to be mentioned that the lower predicted $\mathrm{CF}_{\mathrm{x}}$ radical concentrations by the model only partially explain the lower predicted $\mathrm{CF}^{+}$ion density (assuming that the ion flux is mostly determined by the ion density), since it is shown in Fig. 11 that the concentration of the CF radicals that can directly produce $\mathrm{CF}^{+}$ions by parent ionization is quite low in both the experiments and the simulations. Besides, when comparing to the work of Ref. 27, where a global model coupled to a more complex surface polymer kinetics model was used for a pure $\mathrm{C}_{4} \mathrm{~F}_{8}$ ICP source, it is found that the $\mathrm{CF}^{+}$density predicted by this global model is still the lowest among the three light ions $\left(\mathrm{CF}^{+}, \mathrm{CF}_{2}{ }^{+}\right.$, and $\mathrm{CF}_{3}{ }^{+}$) at all considered discharge conditions, hence in agreement with our simulations presented in Fig. 10 above. The fact that several experimental works revealed that the $\mathrm{CF}^{+}$ ions are the most predominant ions in the $\mathrm{C}_{4} \mathrm{~F}_{8}$ ICP source $^{25,57,58}$ and that both our hybrid model with relatively simple surface kinetics, as well as the global model with more complete polymer surface kinetics, fail to predict this higher $\mathrm{CF}^{+}$ion density, indicates that some mechanisms for the formation of $\mathrm{CF}^{+}$ions are still missing from both models. It is not yet clear which mechanisms are missing, but some candidates might be the direct production of $\mathrm{CF}^{+}$ions by ion bombardment on the surface polymer, or bulk dissociative charge exchange of ions with polymeric heavy fc neutrals. Such processes have not yet been included in the models for $\mathrm{C}_{4} \mathrm{~F}_{8}$ reported up to now. ${ }^{25-27,32,37}$

\section{CONCLUSION}

In this paper, the fragmentation of $\mathrm{a}_{4} \mathrm{~F}_{8}$ plasma in an ICP reactor was numerically investigated by the HPEM model, for a range of different gas pressures and applied powers. More specifically, we focused on the densities of the various fc neutrals and positive ions, the dissociation degree, the density ratio of $\mathrm{F}$ vs. $\mathrm{C}_{\mathrm{x}} \mathrm{F}_{\mathrm{y}}$ radicals, the ratio of the neutral vs. ion densities, and the fractions of the various fc neutrals and ions. The simulations show that the power and pressure have an important effect on the $\mathrm{C}_{4} \mathrm{~F}_{8}$ fragmentation. To analyze the results, we studied the main primary and secondary processes, based on electron impact reactions, for the generation of the various fc species. Besides, we also analyzed the electron density and temperature and the EEPFs, as they also play a role in determining the fragmentation behavior. The major conclusions can be summarized as follows:

(1) The dissociation degree of the $\mathrm{C}_{4} \mathrm{~F}_{8}$ plasma decreases with rising gas pressure, because there are more $\mathrm{C}_{4} \mathrm{~F}_{8}$ molecules in the chamber, which cannot all be dissociated due to the lower fraction of high-energy electrons responsible for dissociation. On the other hand, the dissociation degree increases with applied power, due to the more prominent electron impact dissociation collisions.
(2) The $F$ vs. $C_{x} F_{y}$ density ratio decreases with rising gas pressure, because of the rise in $\mathrm{C}_{\mathrm{x}} \mathrm{F}_{\mathrm{y}}$ density (which is mainly generated by primary processes), and the drop in $\mathrm{F}$ density (which is exclusively produced by secondary processes). On the other hand, the density ratio increases with rising power, as the secondary processes, responsible for the formation of the $\mathrm{F}$ atoms, are more predominant at high power.

(3) At high enough power, the total fc neutral density saturates with power, because of depletion of $\mathrm{C}_{4} \mathrm{~F}_{8}$ in the heating region, so dissociation of $\mathrm{C}_{4} \mathrm{~F}_{8}$, creating new radicals, is of minor importance. As far as the ions are concerned, at high power the secondary ionization processes dominate, and because the lumped $\mathrm{CF}_{\mathrm{x}}$ density has the highest concentration, ionization from these fc species is most important and therefore, the $\mathrm{CF}_{\alpha}{ }^{+}$ion density increases most with power.

(4) At high pressure, the secondary ionization processes for fc ions are more important than the primary processes, which explain why the $\mathrm{C}_{4} \mathrm{~F}_{7}{ }^{+}$density, produced exclusively by a secondary process, significantly increases.

(5) At increasing pressure, the $\mathrm{CF}_{\alpha}{ }^{+}$density, as well as its fraction in the total fc ion population, significantly decreases, because the high-energy tail of EEPF is severely depleted, and the generation reactions for $\mathrm{CF}_{\alpha}{ }^{+}$ ions, including both secondary and primary processes, have high threshold energies. Moreover, the fraction of $\mathrm{CF}_{\mathrm{x}}$ in the total fc neutral population also decreases with pressure, which reinforces the trend of the drop in $\mathrm{CF}_{\alpha}{ }^{+}$ density (and fraction), as the secondary ionization process dominates at high pressure (see point (4) above).

(6) At high power, the $\mathrm{C}$ and $\mathrm{F}$ densities increase, as they are exclusively produced by secondary processes, which become more important at high power. In contrast, at high pressure, the $\mathrm{C}$ and $\mathrm{F}$ densities significantly decrease, because the rates of secondary dissociation processes are reduced.

To summarize, all these trends in the dissociation degree, the density ratios of $\mathrm{F}$ vs $\mathrm{C}_{\mathrm{x}} \mathrm{F}_{\mathrm{y}}$ and of ions vs neutrals, the fc neutral and ion fractions, the fragmentation pattern and the EEPFs, are closely related with each other, and can be explained by the reaction set.

Finally, the calculation results, more specifically the dissociation degree, the density ratio of $\mathrm{F}$ vs. $\mathrm{C}_{\mathrm{x}} \mathrm{F}_{\mathrm{y}}$, and their variation with pressure and power, are found to be in good correlation with experiments from the literature. We verified the model by applying it exactly to experimental conditions from literature and making a one-to-one comparison. In general, the agreement is reasonable, in view of the complexity, but there are some discrepancies, which can probably be attributed to the simplified polymer surface kinetics assumed in our model. Nevertheless, as the overall agreement is reasonable, we believe that the reaction scheme included in the model, even with a simple surface reaction set, can be used to explain the general bulk plasma fragmentation of this $\mathrm{C}_{4} \mathrm{~F}_{8}$ ICP source. This is useful for the semiconductor industry, since the relative importance of the various reactive species influences the $\mathrm{Si}$-based material 
etching processes, based on fc film polymerization, etching, and sputtering.

\section{ACKNOWLEDGMENTS}

The work was conducted during a postdoc fellowship of S. X. Zhao at the University of Antwerp and was financially supported by the Belgian Federal Science Policy. Moreover, this work was also financially supported by the joint research project within the framework of the agreement between the Fund for Scientific Research Flanders (FWO) and MOST, by the National Natural Science Foundation of China (NSFC) (Grant Nos. 11075029 and 11305023), doctoral fund of Ministry of Education of China 20130041120054, and DUT13RC(3)19 foundation. The calculations were carried out using the Turing HPC infrastructure at the CalcUA core facility of the Universiteit Antwerpen, a division of the Flemish Supercomputer Center VSC, funded by the Hercules Foundation, the Flemish Government (department EWI) and the Universiteit Antwerpen.

${ }^{1}$ H. Yasuhiro, K. Kazuhiro, S. Haruo et al., J. Vac. Sci. Technol., A 13(3), 801 (1995)

${ }^{2}$ C. T. Nelson, S. P. Sant, L. J. Overzet et al., Plasma Sources Sci. Technol. 16, 813 (2007).

${ }^{3}$ K. Ishikawa, S. Hayashi, and M. Sekine, J. Appl. Phys. 93(3), 1403 (2003).

${ }^{4}$ X. Li, X. F. Hua, L. Ling et al., J. Vac. Sci. Technol., A 20(6), 2052 (2002).

${ }^{5}$ R. P. Jayaraman, R. T. McGrath, and G. A. Hebner, J. Vac. Sci. Technol., A 17(4), 1545 (1999).

${ }^{6}$ M. Haverlag, A. Kono, D. Passchier et al., J. Appl. Phys. 70(7), 3472 (1991).

${ }^{7}$ G. S. Oehrlein, Y. Zhang, D. Vender et al., J. Vac. Sci. Technol., A 12(2), 323 (1994).

${ }^{8}$ M. A. Blauw, T. Zijlstra, and E. van der Drift, J. Vac. Sci. Technol., B 19(6), 2930 (2001).

${ }^{9}$ A. A. Ayon, R. L. Bayt, and K. S. Breuer, Smart Mater. Struct. 10, 1135 (2001).

${ }^{10}$ C. Chang, Y. F. Wang, Y. Kanamori et al., J. Micromech. Microeng. 15, 580 (2005).

${ }^{11}$ K. B. Jung, W. J. Song, H. W. Lim et al., J. Vac. Sci. Technol., B 28(1), 143 (2010).

${ }^{12}$ S. Rauf, W. J. Dauksher, S. B. Clemens et al., J. Vac. Sci. Technol., A 20(4), 1177 (2002).

${ }^{13}$ R. J. Belen, S. Gomez, M. Kiehlbauch et al., J. Vac. Sci. Technol., A 24(2), 350 (2006).

${ }^{14}$ D. J. Cooperberg, V. Vahedi, and R. A. Gottscho, J. Vac. Sci. Technol., A 20(5), 1536 (2002).

${ }^{15}$ M. Sekine, Appl. Surf. Sci. 192, 270 (2002).

${ }^{16}$ H. C. Liu, Y. H. Lin, and W. Hsu, Microsyst. Technol. 10, 29 (2003).

${ }^{17}$ S. Takagi, S. Onoue, K. Iyanagi et al., Plasma Sources Sci. Technol. 12, S64 (2003).

${ }^{18}$ M. M. Wang and M. J. Kushner, J. Vac. Sci. Technol., A 29(5), 051306 (2011).

${ }^{19}$ A. Kono and H. Funahashi, J. Appl. Phys. 92(4), 1757 (2002).

${ }^{20}$ G. A. Hebner, J. Appl. Phys. 89(2), 900 (2001).
${ }^{21}$ H. Hayashi, S. Morishita, T. Tatsumi et al., J. Vac. Sci. Technol., A 17(5), 2557 (1999).

${ }^{22}$ M. T. Radtke, J. W. Coburn, and D. B. Graves, J. Vac. Sci. Technol., A 21(4), 1038 (2003).

${ }^{23}$ M. J. Barela, H. M. Anderson, and G. S. Oehrlein, J. Vac. Sci. Technol., A 23(3), 408 (2005).

${ }^{24}$ K. Teii, M. Hori, T. Goto et al., J. Appl. Phys. 87, 7185 (2000).

${ }^{25}$ X. Li, L. Ling, X. F. Hua et al., J. Vac. Sci. Technol., A 22, 500 (2004).

${ }^{26}$ A. V. Vasenkov and M. J. Kushner, J. Appl. Phys. 95, 834 (2004).

${ }^{27}$ G. Kokkoris, A. Goodyear, M. Cooke et al., J. Phys. D: Appl. Phys. 41, 195211 (2008).

${ }^{28}$ K. Miyata, M. Hori, and T. Goto, J. Vac. Sci. Technol., A 14(4), 2343 (1996).

${ }^{29}$ K. Miyata, K. Takahashi, S. Kishimoto et al., Jpn. J. Appl. Phys., Part 2 34, L444 (1995).

${ }^{30}$ T. Tatsumi, H. Hayashi, S. Morishita et al., Jpn. J. Appl. Phys., Part 1 37, 2394 (1998).

${ }^{31}$ S. Samukawa and T. Mukai, J. Vac. Sci. Technol., A 17(5), 2463 (1999).

${ }^{32}$ S. Rauf and P. L. G. Ventzek, J. Vac. Sci. Technol., A 20, 14 (2002).

${ }^{33}$ K. Teii, M. Hori, M. Ito et al., J. Vac. Sci. Technol., A 18(1), 1 (2000).

${ }^{34}$ H. W. Huang, C. Ye, Y. J. Xu et al., Plasma Sci. Technol. 12(5), 566 (2010).

${ }^{35}$ C. Suzuki, K. Sasaki, and K. Kadota, J. Vac. Sci. Technol., A 16, 2222 (1998).

${ }^{36}$ K. Sasaki, K. Takizawa, N. Takada et al., Thin Solid Films 374, 249 (2000).

${ }^{37}$ D. Zhang and M. J. Kushner, J. Vac. Sci. Technol., A 18(6), 2661 (2000).

${ }^{38}$ J. P. Booth, G. Cunge, P. Chabert et al., J. Appl. Phys. 85(6), 3097 (1999).

${ }^{39}$ A. Sankaran and M. J. Kushner, J. Vac. Sci. Technol., A 22(4), 1242 (2004).

${ }^{40}$ A. Sankaran and M. J. Kushner, J. Appl. Phys. 97, 023307 (2005).

${ }^{41}$ M. J. Kushner, J. Phys. D: Appl. Phys. 42, 194013 (2009).

${ }^{42}$ Y. Yang and M. J. Kushner, Plasma Sources Sci. Technol. 19, 055011 (2010).

${ }^{43}$ Y. Yang, M. Strobel, S. Kirk et al., Plasma Processes Polym. 7, 123 (2010).

${ }^{44}$ A. V. Vasenkov, X. Li, G. S. Oehrlein et al., J. Vac. Sci. Technol., A 22(3), 511 (2004).

${ }^{45}$ S. X. Zhao, F. Gao, Y. N. Wang et al., Plasma Sources Sci. Technol. 21, 025008 (2012).

${ }^{46}$ S. X. Zhao, F. Gao, Y. N. Wang et al., Plasma Sources Sci. Technol. 22, 015017 (2013).

${ }^{47}$ G. Font, W. L. Morgan, and G. Mennenga, J. Appl. Phys. 91, 3530 (2002).

${ }^{48}$ G. Christophorou and J. K. Olthoff, J. Phys. Chem. Ref. Data 30, 449 (2001).

${ }^{49}$ R. L. Woodin, M. S. Foster, and J. L. Beauchamo, J. Chem. Phys. 72(7), 4223 (1980).

${ }^{50}$ I. Sauers, L. G. Christophorou, and J. G. Carter, J. Chem. Phys. 71(7), 3016 (1979).

${ }^{51}$ Y. Wang, R. J. Van Brunt, and J. K. Olthoff, J. Appl. Phys. 83(2), 703 (1998).

${ }^{52}$ W. J. Park, J. H. Kim, S. M. Cho et al., Surf. Coat. Technol. 171, 290 (2003).

${ }^{53}$ M. A. Lieberman and A. J. Lichtenberg, Principles of Plasma Discharges and Materials Processing, 2nd ed. (Wiley-Interscience, New York, 2005).

${ }^{54}$ M. Sekine, Pure Appl. Chem. 74(3), 381 (2002).

${ }^{55}$ H. Nakagawa, S. Morishita, S. Noda et al., J. Vac. Sci. Technol., A 17(4), 1514 (1999).

${ }^{56}$ D. Bose, S. Rauf, D. B. Hash et al., J. Vac. Sci. Technol., A 22, 2290 (2004).

${ }^{57}$ A. N. Goyette, Y. Wang, M. Misakian et al., J. Vac. Sci. Technol., A 18, 2785 (2000).

${ }^{58}$ Y. Chinzei, T. Ichiki, N. Ikegami et al., J. Vac. Sci. Technol., B 16, 1043 (1998). 